

\section{WHAT MATTERS}

A diagnosis of prostate cancer was life-changing news for over 170,000 people per year
Cutting edge treatments that are noninvasive so he can enjoy a life-changing trip around the world

\section{cancernetwork}

home of the journal ONCOLOGY

Oncology and CancerNetwork lead the industry with the latest insights from key opinion leaders in oncology through articles, peer perspectives, and interactive content that translates into clinical application for today's practicing oncologist. Timely. Practical. Relevant. 


\section{IN THIS ISSUE}

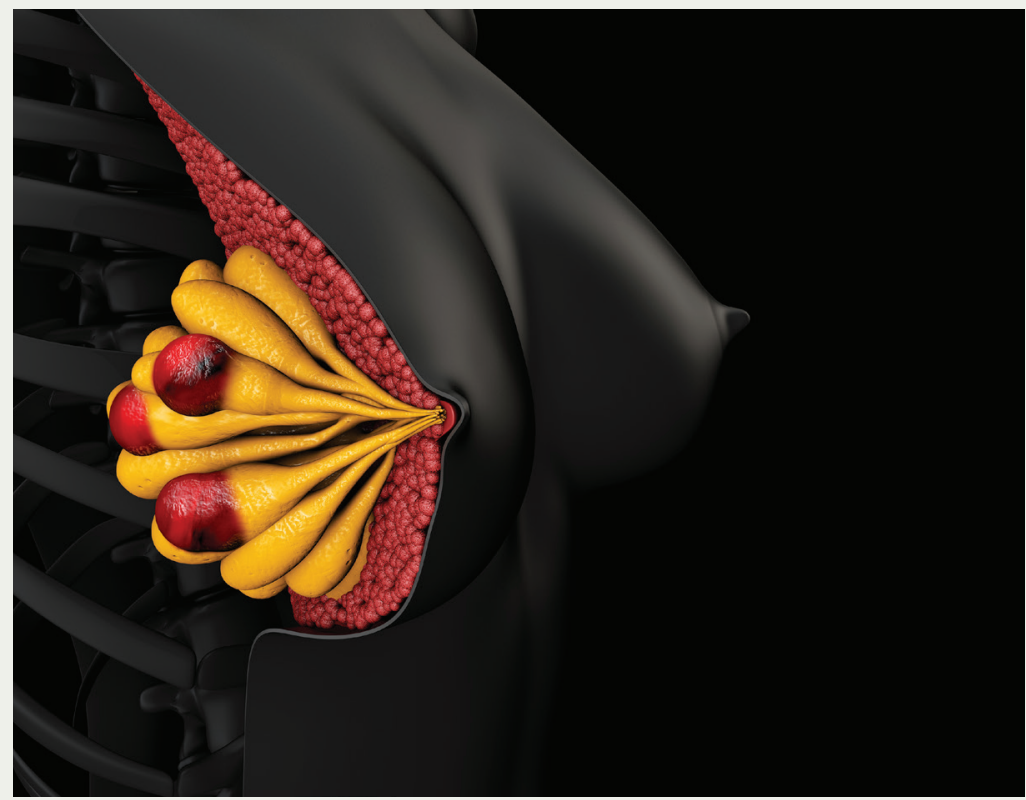

130 WOMEN'S CANCER: Cover

Joyce A. O'Shaughnessy, MD

PERSPECTIVE: Natasha Hunter, MD, and Nancy E. Davidson, MD

ONCOLOG $Y^{\circledR}$ recently sat down with Joyce A. O’Shaughnessy, $\mathrm{MD}$, to discuss the current trends in breast cancer treatment and the avalanche of agents moving through the development pipeline.

120

LUNG CANCER: Case Study

Recurrent Small Cell Carcinoma of the Lung With Cutaneous Metastasis in Breast

Mehmet Sitki Copur, MD, FACP; Adam Horn, MD; John Allen, MD; Carlene Springer, APRN; and Thomas Zusag, MD

The case of a 57-year-old woman with a subcutaneous nodule in the lower middle of her right breast.

125

GU CANCER: Clinical Quandary

69-Year-Old Man With Castration-Resistant Prostate Cancer Progressing After Docetaxel and Androgen Receptor-Targeting Agent

Eduardo Gonzalez-Ochoa, MD; Haydee Verduzco-Aguirre, MD; E. David Crawford, MD; and María T. Bourlon, MD, MSc

\section{cancernetwork.com}

Visit CancerNetwork.com, home of the journal ONCOLOGY ${ }^{B}$ and a web destination for oncologists seeking expert peer perspectives, podcasts, and other clinically practical features.

\section{NEWS}

Findings Support Screening of COVID-19 in Patients With Cancer

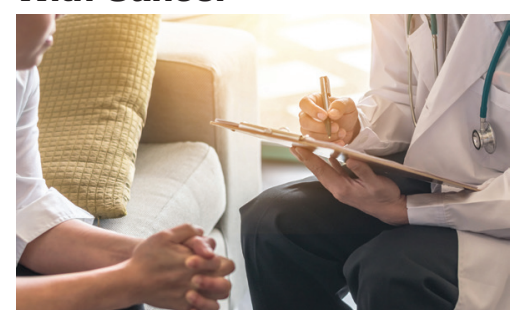

Cancernetwork.com/ COVID19ScreeningCancer

\section{NEWS}

Outcomes of the SARSCoV-2 Infection in Patients With Cancer Treated in China

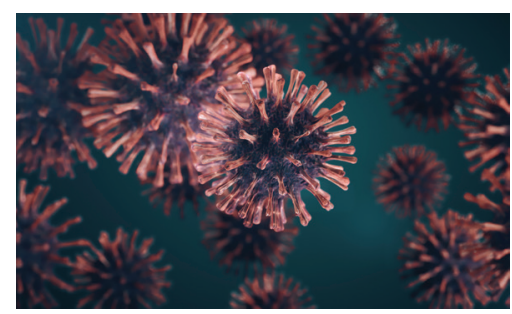

Cancernetwork.com/ COVID19CancerOutcomes

\section{NEWS}

Study Highlights Importance of Progression-Related End Points in Cancer

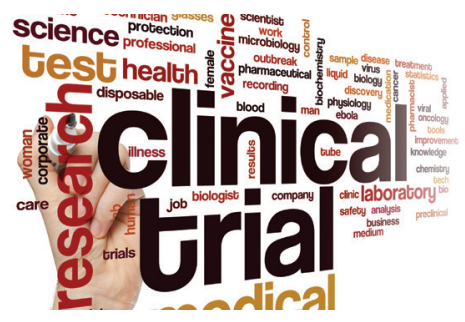

Cancernetwork.com/ProgressionRelatedEndPoints 
Chairman's Letter

118 The Rapid Evolution of Breast Cancer Care

Mike Hennessy Sr

Letter to the Reader

119 Oncology in the Time of COVID-19

Howard S. Hochster, MD

\section{GI CANCER: FDA Approval 137 FDA Approves Nivolumab Plus Ipilimumab for the Treatment of Advanced HCC}

Kevin Wright

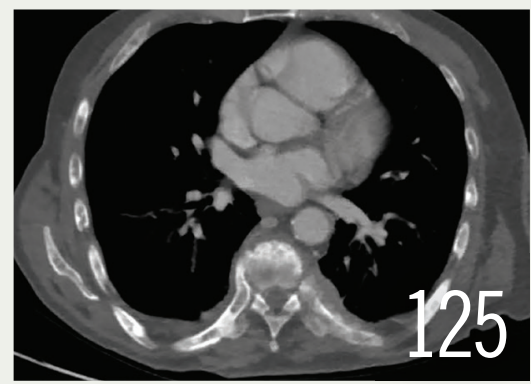

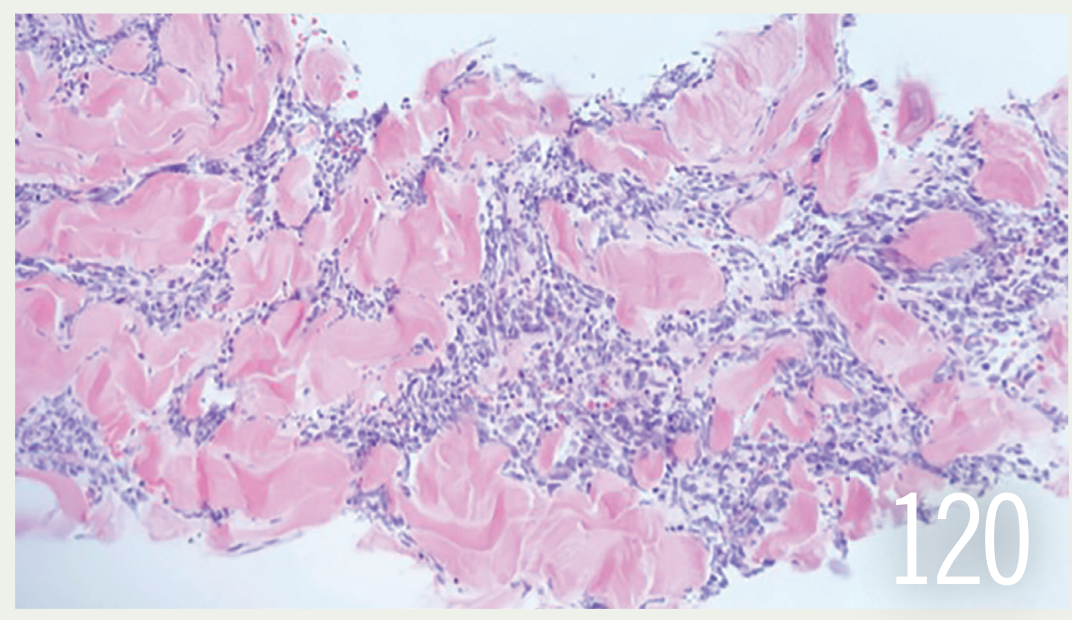

IMMUNOTHERAPY: Review 139 HPV and the Immune System in Head and Neck Cancers

Madison Grinnell; Mridula Krishnan, MD; and Apar Kishor Ganti, MD, MS

The role of immunotherapy in HPV-associated HNSCC along with the evidence and perspective behind differing therapeutic considerations.
HEMATOLOGIC MALIGNANCIES: Continuing Medical Education 144 Minimal Residual Disease and Its Impact on the Clinical Management of Patients With Leukemia

Elias Jabbour, MD

Published in affiliation with

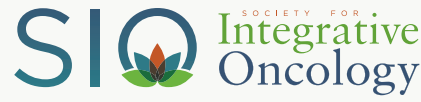

\section{EDITORIAL}

KRISTIE L. KAHL Editorial Director KEVIN WRIGHT Senior Editor

HANNAH SLATER Assistant Editor MATTHEW FOWLER Assistant Editor ROBERT MCGARR Creative Director KRISTEN MORABITO Art Director RACHEL KEATLEY Graphic Designer

\section{Publishing \& SALES}

BRIAN HAUG Executive Vice President 609-325-4780 • bhaug@mmhgroup.com MARC MATHEWS Vice President Oncology 609-819-5245 mmathews@mjhlifesciences.com MICHELLE JANIN Director of Sales 732-429-4316•mjanin@mmhgroup.com FRANK GABRIEL National Accounts Associate • 646-306-9564 fgabrie@@mihassoc.com

\section{AUDIENCE} DEVELOPMENT

KELLY KEMPER Audience Development Manager

\section{CORPORATE}

MIKE HENNESSY SR Chairman \& Founde JACK LEPPING Vice Chairman MIKE HENNESSY JR President \& CEO NEIL GLASSER, CPA/CFE Chief Financial Officer

TOM TOLVÉ Executive Vice President, Operations
SILAS INMAN Senior Vice President,

JEFF BROWN Executive Creative

JOHN MORICONE Senior Vice Presiden I.T. \& Enterprise Systems

JoY PUZzo Senior Vice President Audience Generation \& Product Fulfillment

SHARI LUNDENBERG Vice President, Human Resources \& Administration CHRIS HENNESSY Vice President, Business Intelligence AMY ERDMAN Vice President, Corporate Branding \& B2B Marketing
Director, Creative Services

\section{SUBSCRIPTIONS}

888-527-7008

\section{PER $=$ THE EDITORS ARE PLEASED TO ANNOUNCE the availability of our new parent company's continuing education activities. gotoper.com We've picked this one especially for our ONCOLOGY ${ }^{\circledR}$ readers. Go to: https://bit.ly/2IRAknZ}

Advertiser and advertising agency recognize and accept that the following language appears within the publication: "All statements, including product claims, are those of the person or organization making the statement or claim. The publisher does not adopt any such statement or claim as its own, and any such statement or claim does not necessarily reflect the opinion of the publisher."

Advertiser and advertising agency accept and assume liability for all content (including text, representations, illustrations, opinions and facts) of advertisements printed, and also assume responsibility for any claims made against the publisher arising from or related to such advertisements. In the event that lega action or a claim is made against the publisher arising from or related to such advertisements, advertiser and advertising agency agree to fully defend, indemnify and hold harmless the publisher, and to pay any judgment, expenses and legal fees incurred by the publisher as a result of said legal action or claim. The publisher reserves the right to reject any advertising which he feels is not in keeping with the publication's standards.

Publisher is not liable for delays in delivery and/or non-delivery in the event of an act of God, action by any government or quasi-governmental entity, fire, flood, insurrection, riot, explosion, embargo, strikes (whether legal or illegal), labor or material shortage, transportation interruption of any kind, work slow-down, or any condition beyond the control of publisher affecting production or delivery in any manner.
ONCOLOG ${ }^{\odot}$ (ISSN 0890-9091) is published monthly by MultiMedia Healthcare LLC, 2 Clarke Drive, Suite 100 Cranbury, NN 08512. Annual subscription rates: US, $\$ 199$ and Canada, $\$ 219$; students and nurses, $\$ 96$; international, \$249. Single copies: 20 each. Institutional US, \$299; Canada, \$329; international, \$375. Periodicals postage paid at Cranbury, $\mathrm{N}$ and at additional mailing offices. POSTMASTER: Please send address changes to Oncology PO Box 457, Cranbury NJ 08512-0457, USA. Publications Mail Agreement № 40612608. Return Undeliverable Canadian Addresses to: IMEX Global Solutions, P0 Box 25542 London ON N6C 6B2. Canadian G.S.T number: R-124213133RT001. Printed in U.S.A.

For address changes, please notify the Circulation Department by visiting www. surveymonkey.com/s/subscriptions, or by mail to ONCOLOG ${ }^{\odot}$, $\odot 2020$ MHH Life Sciences, PO Box 457, Cranbury NJ 08512-0457. Send old address, new address and attach a copy of mail label, if possible. 


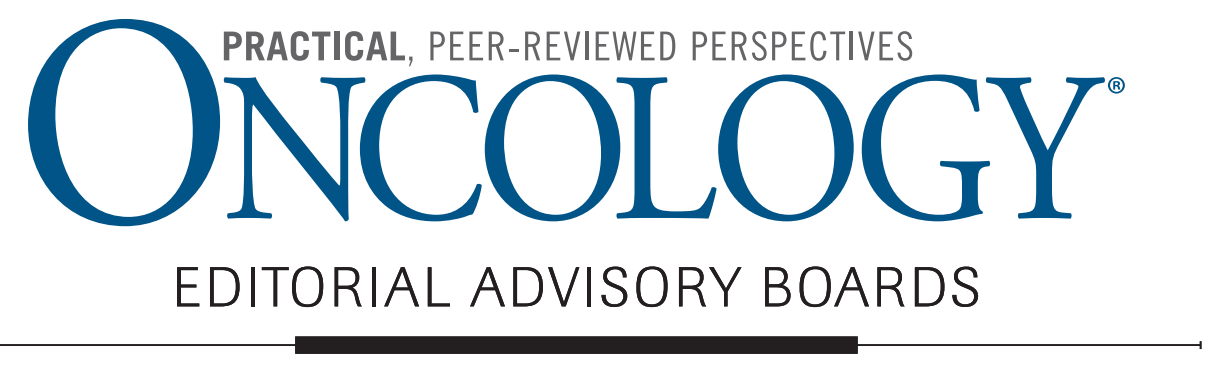

MISSION STATEMENT

ONCOLOGY ${ }^{\circledR}$ and its website, CancerNetwork.com, provide oncologists with the practical, timely, clinical information they need to deliver the highest level of care to their patients. Expert authors and peer review ensure the quality of $O N C O L O G Y^{\circledR}$ and CancerNetwork.com's articles and features. Focused discussions capture key clinical take-aways for application in today's time-constrained practice environment.

\section{EDITORS-IN-CHIEF}

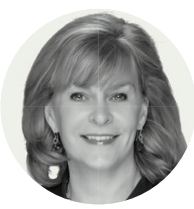

Julie M. Vose, MD, MBA Omaha, NE

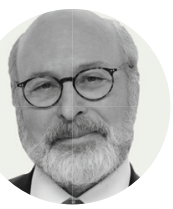

Howard S. Hochster, MD New Brunswick, NJ

\section{EDITORIAL BOARD}

\section{BREAST CANCER}

William J. Gradishar, MD, FACP Chicago, IL I. Craig Henderson, MD San Francisco, CA Tari King, MD Boston, MA

Melanie E. Royce, MD, PhD Albuquerque, NM Vered Stearns, MD Baltimore, MD

CANCER SURVIVORSHIP

Matthew J. Matasar, MD, MS New York, NY

COLORECTAL/GASTROINTESTINAL CANCER

Edward Chu, MD Pittsburgh, PA

Daniel Haller, MD Philadelphia, PA

John L. Marshall, MD Washington, DC

Matthew B. Yurgelun, MD Boston, MA

GENITOURINARY CANCER

L. Michael Glodé, MD, FACP Denver, CO

Paul Mathew, MD Boston, MA

William U. Shipley, MD Boston, MA

GYNECOLOGIC ONCOLOGY

Mario M. Leitao, Jr, MD New York, NY

Franco Muggia, MD New York, NY

HEAD AND NECK CANCER

Apar K. Ganti, MD, MS, FACP Omaha, NE
INFECTIOUS DISEASE

Genovefa Papanicolaou, MD New York, NY

INTEGRATIVE ONCOLOGY

Donald I. Abrams, MD San Francisco, CA Jun J. Mao, MD, MSCE New York, NY

LEUKEMIA/LYMPHOMA

Bruce D. Cheson, MD Washington, DC Christopher Flowers, MD Atlanta, GA Alexandra M. Levine, MD, MACP Duarte, CA

Steven T. Rosen, MD Duarte, CA

John W. Sweetenham, MD, FRCP Salt Lake City, UT

LUNG CANCER

David S. Ettinger, MD Baltimore, MD

James L. Mulshine, MD Chicago, IL

MELANOMA

Richard D. Carvajal, MD New York, NY Ahmad Tarhini, MD, PhD Cleveland, $\mathrm{OH}$ NEURO-ONCOLOGY

Stuart A. Grossman, MD Baltimore, MD Nicole A. Shonka, MD Omaha, NE

PEDIATRIC ONCOLOGY

David G. Poplack, MD Houston, TX
PROSTATE CANCER

Tomasz M. Beer, MD Portland, OR E. David Crawford, MD Denver, CO Series Editor

Judd W. Moul, MD, FACS Durham, NC

PSYCHO-ONCOLOGY

Daniel C. McFarland, Do New York, NY

RADIATION ONCOLOGY

Jay S. Cooper, MD New York, NY

Louis Potters, MD, FACR Hempstead, NY James B. Yu, MD, MHS New Haven, CT

SARCOMA

Kenneth Cardona, MD, FACS Atlanta, GA

SUPPORTIVE AND PALLIATIVE CARE

Russell K. Portenoy, MD New York, NY

Thomas J. Smith, MD, FACP Baltimore, MD

N. Simon Tchekmedyian, MD Long Beach, CA

SURGICAL ONCOLOGY

Burton L. Eisenberg, MD Newport Beach, CA Armando Giuliano, MD Los Angeles, CA

COMMUNITY ONCOLOGIST ADVISORY BOARD Community oncologists who are interested in joining are welcome to contact ONCOLOGY $Y^{\circledR}$ at cancernetwork@mjhlifesciences.com

Caroline Behler, MD San Francisco, CA Ralph V. Boccia, MD Bethesda, MD Adam M. Boruchov, MD Hartford, CT Michelle S. Boyar, MD Bronxville, NY Nitin Chandramouli, MD Salt Lake City, UT M. Sitki Copur, MD, FACP Grand Island, NE Editor-At-Large

William Donnellan, MD Nashville, TN David Eagle, MD Mooresville/Huntersville, NC
Erika P. Hamilton, MD Nashville, TN Ted Huang, MD Portland, OR Barbara L. McAneny, MD Albuquerque, NM Nancy Mills, MD Bronxville, NY Sudhanshu B. Mulay, MD Hartford, CT W. Charles Penley, MD Nashville, TN Jondavid Pollock, MD Wheeling, WV Steven Powell, MD Sioux Falls, SD Ryan Ramaekers, MD Grand Island, NE
Sonia Seng, MD Fairhaven, MA Stephanie Smith-Marrone, MD Bronxville, NY Christian Thomas, MD Colchester, VT Jacqueline Vuky, MD Portland, OR Raymond Wadlow, MD Fairfax, VA Carolyn Wasserheit-Lieblich, MD Bronxville, NY Tracey F. Weisberg, MD Scarborough, ME Denise Yardley, MD Nashville, TN

Amelia Zelnak, MD, MSc Cumming, GA Richard Zuniga, MD Lowell, MA 


\section{The Rapid Evolution of Breast Cancer Care}

The treatment landscape for breast cancer continues to evolve at an accelerating pace. Because of an expanding arsenal of targeted therapies, survival rates are increasing, and patients are living longer and more meaningful lives. But with new therapeutic options come complex decision making, and a need to effectively disseminate the growing body of knowledge for researchers and community clinicians.

In this issue of ONCOLOGY ${ }^{\circledR}$, we spoke with Joyce A. O'Shaughnessy, MD, chair of Breast Cancer Research and chair of Breast Cancer Prevention Research at Baylor-Sammons Cancer Center and the chair of The US Oncology Network, about recent treatment breakthroughs in the breast cancer space, the abundance of promising therapies moving through the approval pipeline, and the challenges of keeping up with the rapid pace of discovery.

"We've had a sea change in breast cancer just within the last 6 months," says O'Shaughnessy of the recent discoveries. "You've got to now go looking [for the mutations]. You've got to sequence the breast cancer."

O'Shaughnessy also discusses the crucial role that conferences such as the Miami Breast Cancer Conference play in educating clinicians. "It's because of the rapid pace of discovery," says O'Shaughnessy about the need for these events. "It's because there's so much new data that you can apply tomorrow in your practice...it's just really the practical optimal management of your patient Monday morning."

Also in this issue, you will read of 2 patient scenarios: a 69-year-old man with a history of metastatic prostate cancer, and a 57-year-old woman presenting with a nodule on her breast. How do we treat them? Our expert contributors go in depth on best practices and optimal treatments.

Within these pages, you will also find a review of the rapidly evolving immunotherapy applications for head and neck squamous cell carcinoma, and a breakdown of the FDA's recent approval of nivolumab (Opdivo) plus ipilimumab (Yervoy) as a second-line treatment for advanced hepatocellular carcinoma.

I hope you find our journal helpful in caring for your patients through what is likely one of the most challenging times in their lives. As always, thank you for reading. parent company, MJH Life Sciences ${ }^{\text {TM }}$

cancernetwork.con Need to know more? For more great content check out our website.

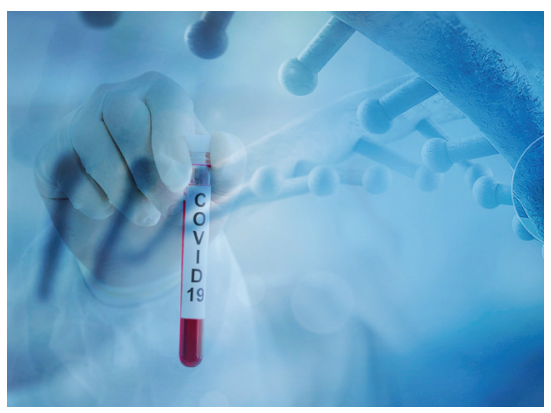

Jeffrey S. Weber, MD, PhD, Discusses Anti-IL-6 Agents in Treating COVID19-Induced Pneumonia

Cancernetwork.com/COVID19Pneumonia

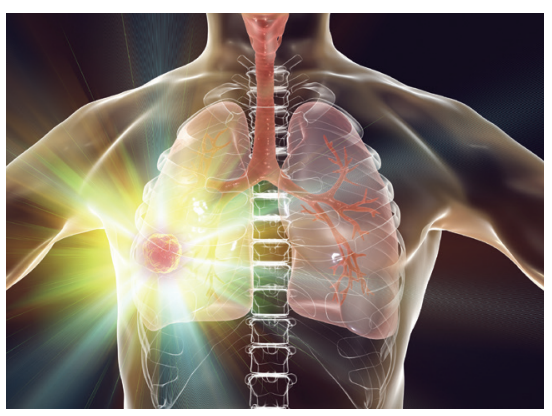

Artificial Intelligence Could Help Predict Tumor Sensitivity for Patients With NSCLC

Cancernetwork.com/AI_TumorSensitivity

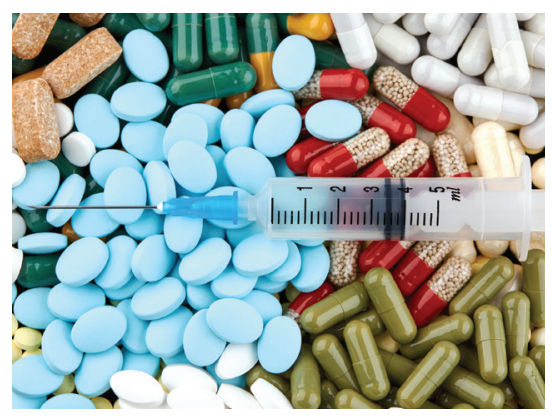

Polypharmacy in Patients with Cancer Over 65 May Predict Hospitalization

Cancernetwork.com/PolypharmacyCancerPatients 


\title{
Oncology in the Time of COVID-19
}

\author{
Howard S. Hochster, MD \\ Associate Cancer Director and Distinguished Professor of Medicine \\ Rutgers Cancer Institute of New Jersey and Rutgers School of Medicine
}

W e are facing difficult decisions and choices as we await the tsunami of coronavirus disease 2019 (COVID-19) cases. Despite the experience of our Chinese colleagues and their government through January, we did not anticipate the surge of infection and institute appropriate contagion policies at entry points and ramp up our medical supplies and capacity. As shown by recent graphs, we are about to hit the exponential phase of the outbreak, on track with China, Italy, and the rest of Europe. Britain may prove the unfortunate exception as they eschewed social distancing for the concept of "herd immunity" until just recently. The British National Health Service has less capacity than other systems; therefore, it is less able to react to this policy. Conversely, the countries that have "flattened the curve," including Taiwan, South Korea, and Singapore, were the ones who developed effective strategies during the prior severe acute respiratory syndrome (SARS) epidemic. They instituted aggressive screening at entry points and quarantining of suspected infected individuals.

As I walk through the streets of Manhattan today, I am reminded of walking through a ghostly Times Square on 9/11. All aspects of communal life have ground to a halt for the foreseeable future. Cultural institutions have shut down. We are sheltering in place. We, at Rutgers, have delayed elective sur- geries, exchanged in-person routine follow-ups for phone or telemedicine interactions, and reduced staff gatherings or conferences in favor of video conferencing. Walking through the quiet hospital today seems like a slow weekend day, yet we know that soon we will be overwhelmed. We must learn the appropriate lessons for the next inevitable pandemic.

As Governor Andrew Cuomo of New York recently stated, if you do the math, you will break out in a sweat, hives, and palpitations. Nine million people live in New York City (NYC). If one-third of the population are infected, there will be 3 million cases, and if $10 \%$ require hospital-level care, 300,000 hospital beds will be needed. If $1 \%$ require intensive care unit (ICU)-level care and ventilators, that means 30,000 intensive beds will be needed. NYC has about 27,000 hospital beds and 5000 ICU beds, not to mention an inadequate number of medical professionals, including respiratory care therapists. I spent 30 years training and attending at Bellevue Hospital and New York University, and was on the frontline of the AIDS epidemic. I know there is no excess capacity. There is no excess capacity in NYC hospitals and our facilities are on the edge of being overwhelmed.

The federal government has failed to prepare in advance for this crisis, lead during the crisis, or plan for its aftermath. Blame has been shifted to prior administrations and current efforts have been shifted to state and city governments. Federal responsibility has been absent even though we are dealing with an infectious agent that does not recognize geographic or political boundaries, race, ethnicity, or political affiliation. We need a surge capacity of 5 to 10 times the current capacity. Healthcare workers are on the frontline, yet we do not have the basic equipment to fight this war. The federal government should nationalize medical supply production and acquisition to ensure supply and prevent crippling price gouging. A coordinated federal response is necessary to prevent our tightly stretched medical network from breaking.

What are we facing and what are we doing:

1. Lack of testing is a critical problem. We are quarantining our staff who have had fevers despite minimal or no exposure. We need tremendous access to nucleic acid testing to screen those who are symptomatic and those who are asymptomatic, yet are potentially exposed. We are forcing desperately needed medical personnel to shelter in place since we cannot tell who is infected with COVID-19. We also need increased access to enzyme-linked immunosorbent assay testing for immunoglobulin (Ig) $\mathrm{M}$ and $\operatorname{IgG}$ antibodies to Continued on page 138 


\section{Recurrent Small Cell Carcinoma of the Lung With Cutaneous Metastasis in Breast}

Mehmet Sitki Copur, MD, FACP'; Adam Horn, MD²; John Allen, MD³; Carlene Springer, APRN'; and Thomas Zusag, MD ${ }^{1}$ Mary Lanning Healthcare, Morrison Cancer Center, Hastings, Nebraska; ${ }^{2}$ Mary Lanning Healthcare, Pathology Department, Hastings, Nebraska; ${ }^{3}$ Midwest Imaging and Interventional Radiology, Grand Island, Nebraska

\begin{abstract}
Lung cancer remains the leading cause of cancerrelated deaths and the second leading cause of new cancer cases in the United States. Although more commonly involving hilar nodes, the liver, adrenal glands, bones, and the brain, lung cancer can metastasize to almost any organ. Metastases, although rare in the skin may be the first sign of a lung cancer or cutaneous metastases may present as a sign of recurrent disease. The incidence of cutaneous metastases from lung cancer has been reported in approximately $1 \%$ to $12 \%$ of cases and was associated with poor prognosis. Although cutaneous metastasis from small cell lung cancer is a rare occurrence, cutaneous metastasis involving the breast is even less common. Here, we present a case of recurrent small cell lung cancer presenting with a firm purplish cutaneous metastatic nodule in the right breast.
\end{abstract}

Keywords: Small cell lung cancer, cutaneous metastases in breast

\section{Background}

Internal malignancies leading to metastases in the skin are rare with a reported incidence of $2 \%$ in 5 large autopsy studies. ${ }^{1}$ Cutaneous metastasis occurs when cells from a cancer in the body spread to the skin through the lymphatic system or bloodstream, or the cancer cells may spread directly to the skin through a sur- gical scar. Cutaneous metastases can occur after the primary cancer has been diagnosed, or in some cases, these lesions may be the first presenting sign of the cancer. Lung cancer is likely responsible for the majority of cutaneous metastases in men and is the second leading cause of cutaneous metastases in women after breast cancer. ${ }^{2}$ The most commonly re- ported metastatic skin lesions originate from primary breast, lung, and colon cancers. Other cancers that have the potential for cutaneous metastasis include melanoma, and those of the kidney, oral cavity, cervix, ovaries, and pancreas. Cutaneous metastases from kidney and oral cavity cancers are more often seen in men and appear on the head and neck regions. Skin findings include fast-growing, firm, mobile, painless pink or purple lesions that may ulcerate.

Breast cancer is the most common form of cutaneous metastasis in women because of its high prevalence rate. Lung cancer is the most common primary malignancy to metastasize to the skin in men. The incidence of cutaneous metastases from lung cancer varies between $1 \%$ to $12 \%$ of cases. ${ }^{3}$ All histological types of lung cancer may cause metastases in the skin. Metastases from lung cancer may be the first sign of lung cancer and clinically it cannot be distinguished from cutaneous metastases originating from other organs. ${ }^{4}$ The most common sites of cutaneous metastases from lung cancer are the chest, abdomen, head, and neck. ${ }^{4,5}$ Clinically, cutaneous metastases occur as round or 
oval nodules, mobile or fixed, firm, and usually skin-colored (sometimes red, dark red, purple, or black). The nodules are usually painless and sometimes can be ulcerated. They can infrequently appear in the form of solitary or grouped papules, plaque-like, zosteriform, erysipelas-like, or as cicatricial alopecia on the scalp. ${ }^{6-8}$ When lesions present on the chest, they may have spread directly from a lung biopsy site. Some lesions of cutaneous lung cancer metastases have been found to run parallel to the blood vessels of the rib cage. Although all different histologic subtypes of lung cancer have been linked to the development of cutaneous metastases, adenocarcinoma or large cell carcinoma of the lung are more frequently reported to metastasize in this fashion. ${ }^{9-11}$ The second most common primary source of metastatic skin disease involving both sexes is colorectal carcinoma. The abdomen and pelvis are the most common locations for these cutaneous metastases to appear. A Sister Mary Joseph node at the umbilicus is a hallmark sign of an underlying gastrointestinal cancer. ${ }^{12,13}$

\section{Case}

A 57-year-old white woman presented with a subcutaneous, purplish, $1.8-\mathrm{cm}$ nodule in the lower middle of her right breast (Figure 1). Past medical history was significant for bilateral silicone breast implants 10 years ago, and a diagnosis of limited-stage small cell lung cancer treated with etoposide/cisplatin plus concurrent chest wall radiation which led to complete remission 1 year ago. In evaluation of this skin nodule, a computed tomography (CT) scan of the chest and an ultrasound-guided biopsy of the breast nodule was performed. The CT scan of the chest confirmed the presence of bilateral breast implants with a 1.8 -cm breast nodule in the middle lower quadrant of the right breast, and a right axillary lymph node (Figure 2). Pathology of tissue from the breast nodule biopsy are shown in Figure 3 and Figure 4.

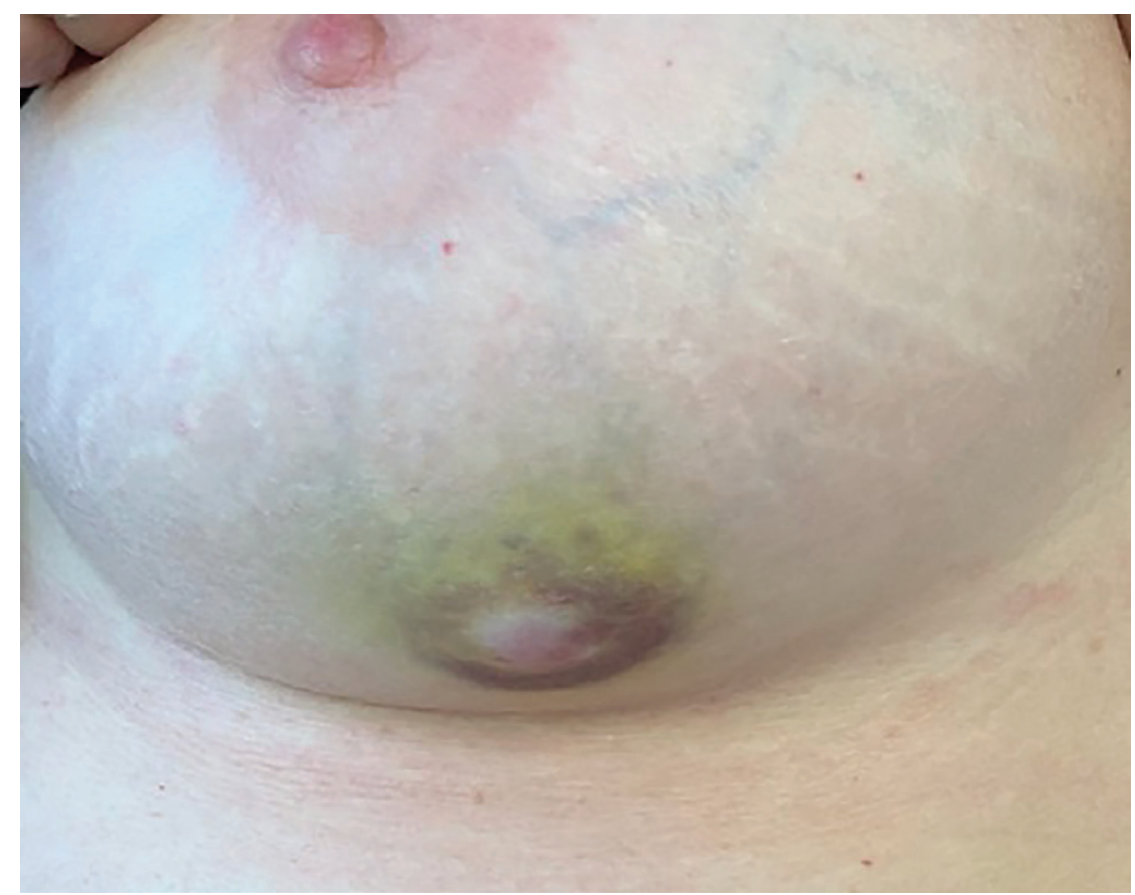

- Figure 1. Breast nodule before chemotherapy

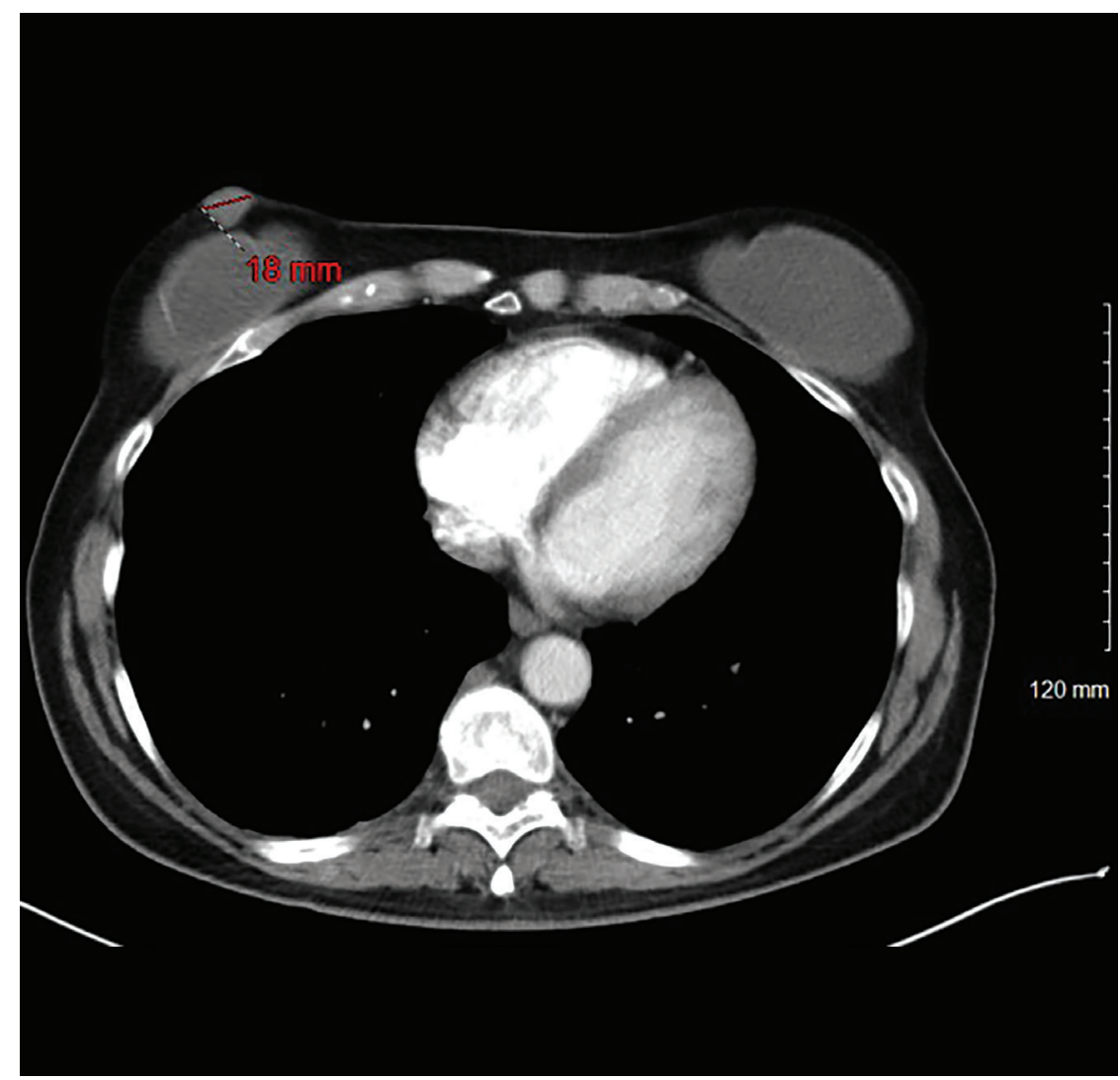

- Figure 2. CT Image of breast nodule before chemotherapy 


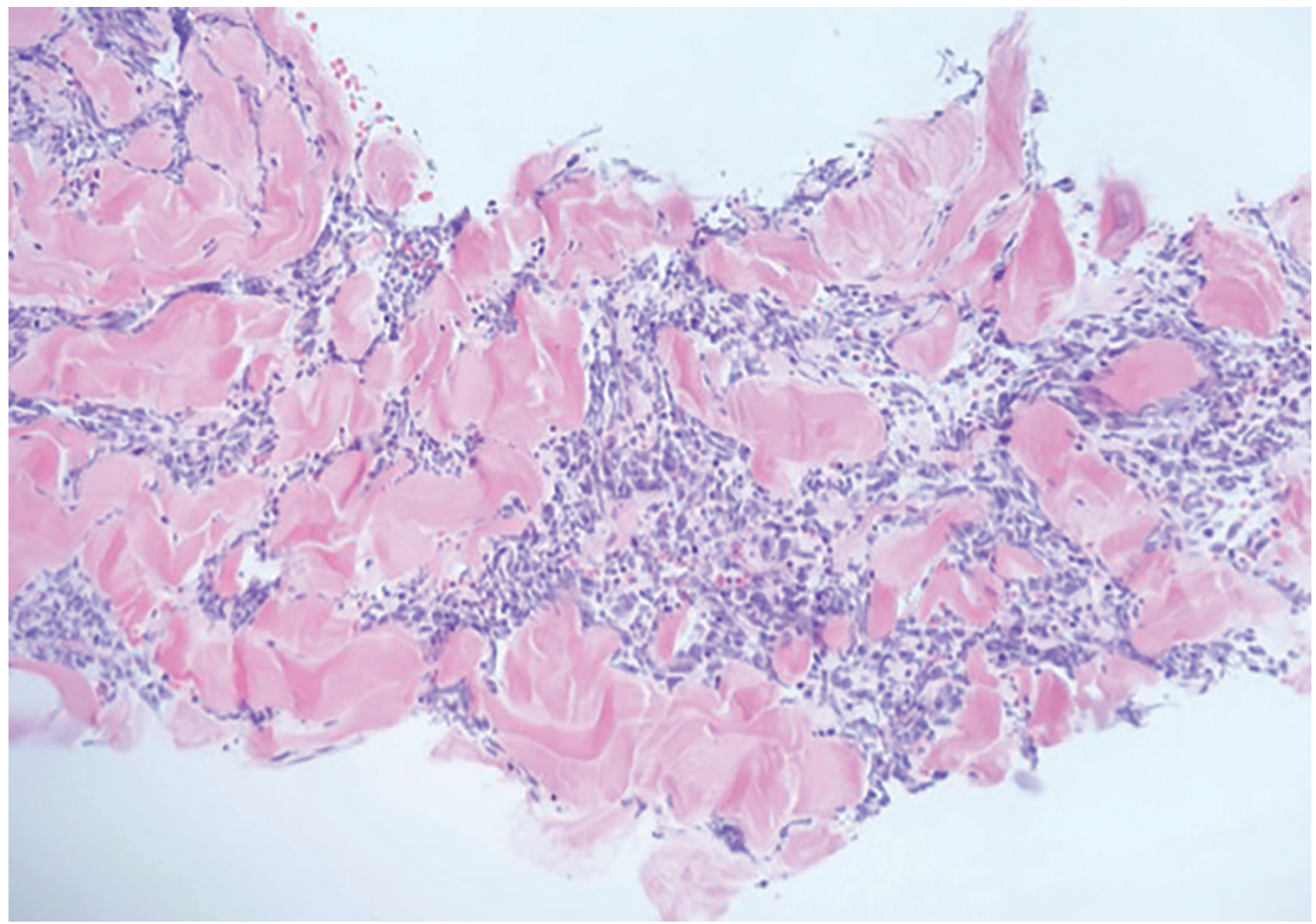

Figure 3. H\&E stain showing malignant cells with scant cytoplasm and nuclear molding

Further work-up with CT scans of the abdomen and pelvis revealed adenopathy in the abdomen adjacent to aorta and left adrenal gland. She was started on second-line chemotherapy with paclitaxel $175 \mathrm{mg} / \mathrm{m} 2$ and carboplatin (area under the concentration time curve of 6) given intravenously every 3 weeks. After 4 cycles of chemotherapy, the breast nodule was no longer visible or palpable on physical exam (Figure 5). Restaging CT scans showed resolution of the breast nodule and axillary and abdominal lymphadenopathy (Figures 6).

\section{Discussion}

Cancer metastasis is an organ-selective process determined by anatomical, biological, and specific microenvironmental factors. ${ }^{14}$ The exact mechanism of lung cancer metastasis to the skin is not clearly understood. Several recent studies have suggested that unique genes and gene signatures might be involved. ${ }^{15,16}$ Lung and breast carcinomas are the most common primary tumors that lead to cutaneous metastases in the skin in men and women, respectively. A number of cancers demonstrate colonization preference to their regions of originlung cancer to the supradiaphragmatic skin and colorectal cancer to the infradiaphragmatic skin regions. Although any histological type of lung cancer is capable of cutaneous metastasis, ${ }^{17}$ adenocarcinomas and large cell carcinomas are the most frequently reported histology in the literature. ${ }^{2,3}$

Small cell carcinoma of the lung seldom metastasizes to the skin. ${ }^{18,19}$ In a review of 4020 cases of cutaneous metastases from systemic cancers, ${ }^{19}$ were of pulmonary origin and only 2 arose from small cell carcinoma. ${ }^{20}$ The malignant cells of small cell carcinoma often affect regional areas via lymphatic channels, but they can also disseminate widely throughout the entire body via hematogenous spread. Metastases in the skin occur when the disease has progressed and they indicate poor prognosis. ${ }^{4,21}$ Survival time after the appearance of cutaneous metastases can be as short as 5 to 6 months. ${ }^{22}$ Patients who present with cutaneous metastases earlier during the disease course have poorer prognosis compared with those who develop skin metastases later in the disease course. $^{23}$

Metastatic lesions are often found on 


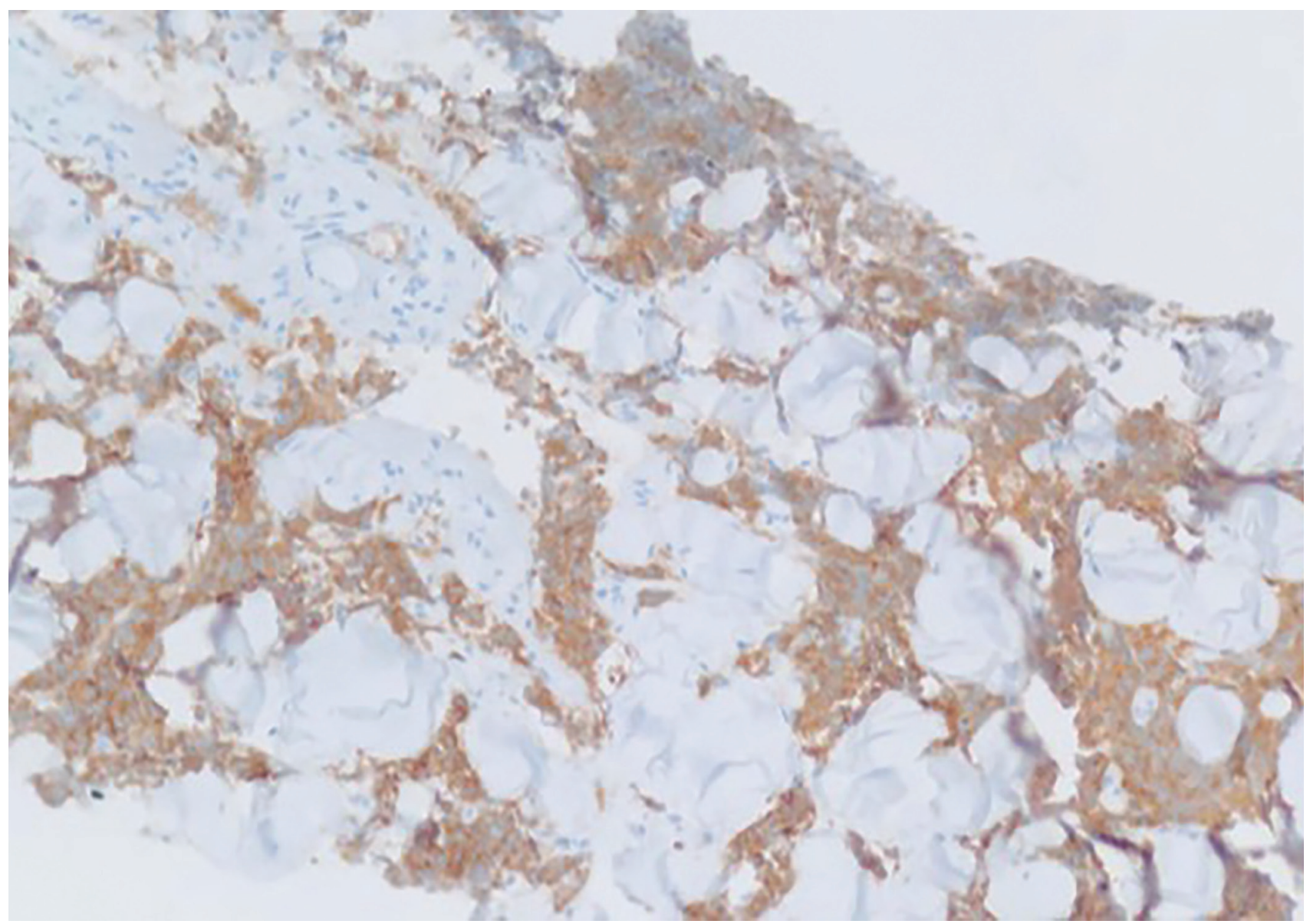

- Figure 4. Malignant cells positive immunohistochemical staining for synaptophysin

the anterior chest, head, scalp, back, and abdomen, and less commonly on the shoulders, flank, and upper and lower extremities. ${ }^{17,20}$ Metastases to the breast from extramammary sites are very unusual and account for $0.4 \%$ to $2.0 \%$ of breast malignancies. ${ }^{22}$ They may present as solitary or multiple lesions with ulcerative or exudative features. Cutaneous manifestations of small cell carcinoma are variable and do not have classic pathognomonic features. Several general characteristics that have been described include nodular, mobile, fast growing, and painless. On biopsy, specimens may appear to remain superficial, or they may invade the dermis and subcutaneous tissue. ${ }^{11}$ In the differential diagnosis of cutaneous metastasis of small cell lung cancer to the breast, pri- mary small cell carcinoma of the breast should be excluded. Primary small cell carcinoma of the breast is a very rare entity with fewer than 30 cases reported in the English-language literature. ${ }^{24}$ The histological findings of primary small cell carcinoma of the breast and of other organs are similar, although their immunohistochemistry staining characteristics are different. The histological detection of in situ intraductal components is important in making the diagnosis of primary small cell carcinoma of the breast along with the immunohistochemical staining for estrogen receptor, progesterone receptor, human epidermal growth factor receptor 2 , thyroid transcription factor 1 (TTF-1), cytokeratin (CK) 7, CK20, chromogranin, and synaptophysin.25 Although primary small cell lung cancer is usually TTF-1-positive, this finding is nonspecific. ${ }^{26}$ It can be positive in small cell carcinoma of many primary sites, and determining the primary organ requires clinical and radiographic correlation. The histologic and immunophenotypic findings of our case were typical for small cell carcinoma, showing cells with fine chromatin, minimal cytoplasm, and nuclear molding. No associated intraductal component was present (Figure 3). Immunohistochemical stains were positive for synaptophysin and chromogranin (Figure 4). CK20 was negative, excluding Merkel cell carcinoma.

\section{Conclusions}

In the advanced stage, small cell lung cancer most frequently metastases to 


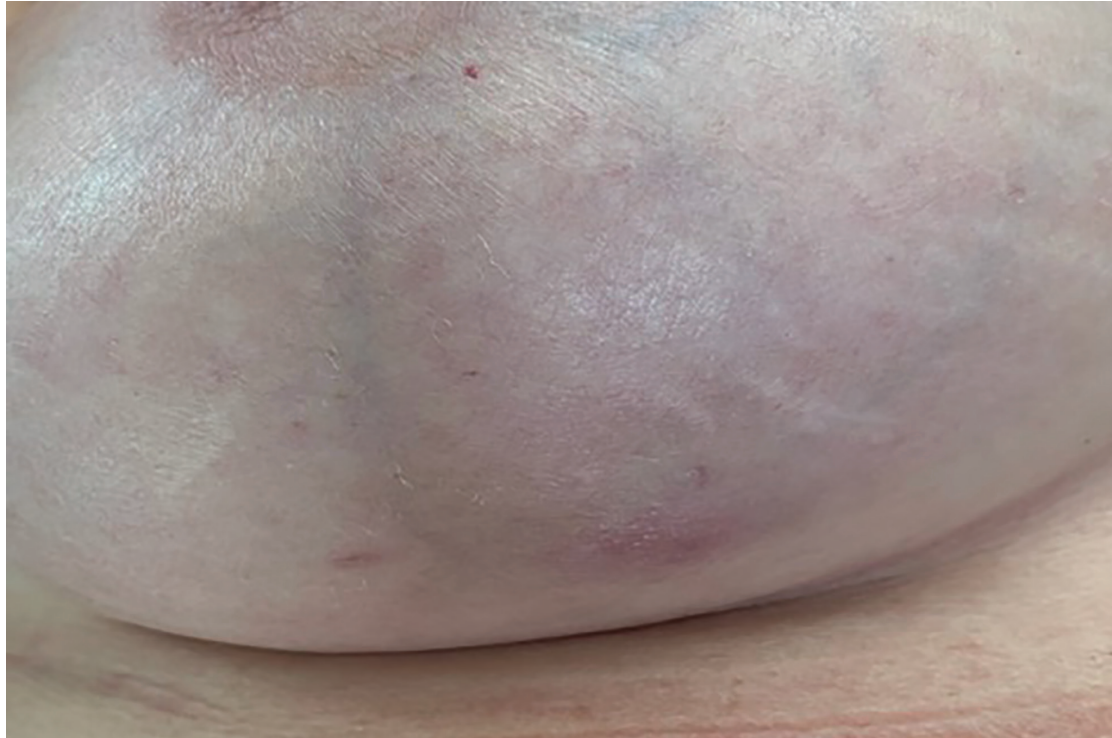

Figure 5. Breast nodule after chemotherapy

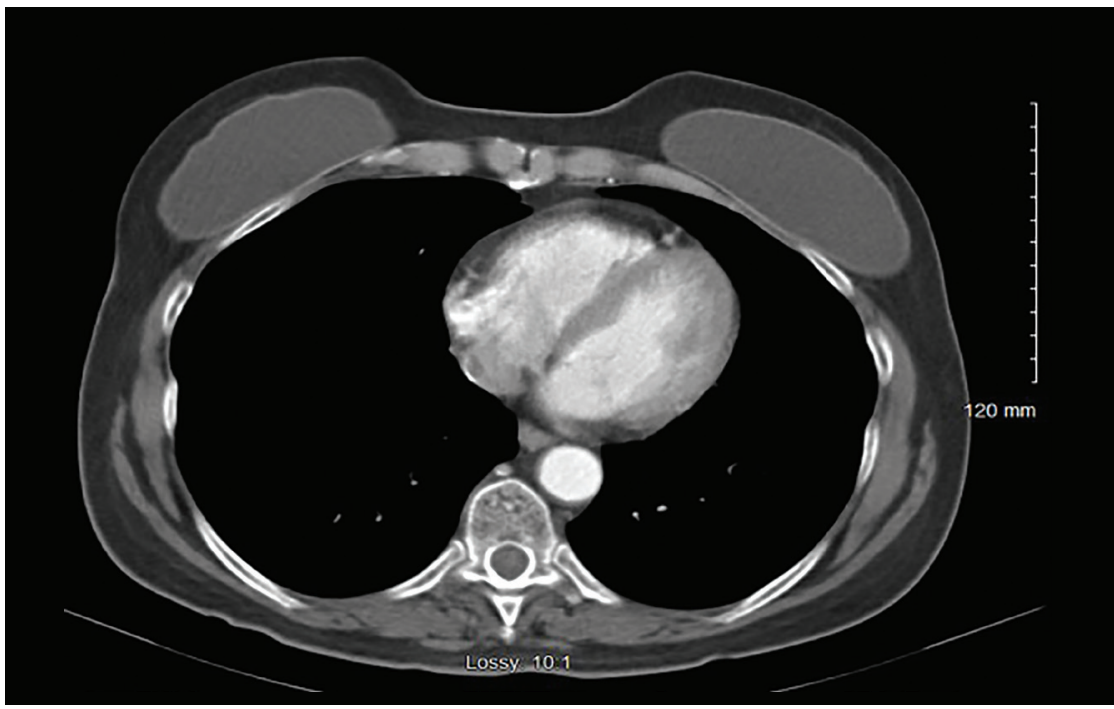

- Figure 6. CT image of breast nodule after chemotherapy the liver, but it can also go to the other organs. Cutaneous metastases may be the first sign or they can develop as a recurrence of previously treated disease (as it was in our case). Due to their nonspecific appearance, these skin lesions can be overlooked or misdiagnosed as benign lesions or as second primary tumors. In our case, the unusual location of this single isolated breast metastasis suggested several differential diagnostic possibilities, including silicone implant-related granuloma, angiosarcoma of the breast, primary small cell carcinoma of the breast, or Merkel cell carcinoma. The presence of cutaneous metastases signifies an advanced-stage disease and carries a poor prognosis. Clinicians should keep this uncommon but important presentation in mind and evaluate suspicious skin lesions appropriately.

\section{Outcome of the Case}

The patient had a complete clinical response to second-line chemotherapy. Her disease is being monitored closely and at the first sign of recurrence, she will be treated with ipilimumab plus nivolumab combination immunotherapy. ${ }^{27}$

FINANCIAL DISCLOSURE: The authors have no significant financial interest in or other relationship with the manufacturer of any product or provider of any service mentioned in this article.

For full reference list, visit:

cancernetwork.com/SCLC_BreastMets

\section{Dr Horn}

is a pathologist at Mary Lanning Healthcare in Hastings, Nebraska.

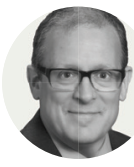

Dr Zusag

is a radiation oncologist at Mary Lanning Cancer Center in Hastings, Nebraska.

\section{Carlene R. Springer}

is a nurse practioner at Mary Lanning Cancer Center in

Hastings, Nebraska.

\section{Dr Copur}

is a medical oncologist/ hematologist at Morrison Cancer Center, Mary Lanning Healthcare in Hastings, Nebraska, and is a professor at the University of Nebraska Medical Center in Omaha, Nebraska. He is also an editor-at-large and a Community Oncology Advisory Board member at ONCOLOGY ${ }^{\circledR}$.

\section{Dr Allen}

received his doctorate of medicine from the University of Nebraska Medical Center in Omaha, where he also completed his residency in diagnostic radiology and fellowship in interventional radiology. He is certified in diagnostic radiology by the American Board of Radiology. 


\section{Progression of Castration-Resistant Prostate Cancer After Docetaxel and Androgen Receptor-Targeting Agent}

Eduardo Gonzalez-Ochoa, MD; Haydee Verduzco-Aguirre, MD; E. David Crawford, MD sand María T. Bourlon, MD, MSc

\section{THE}

CASE

A 69-year-old man with a past medical history of metastatic prostate cancer treated with androgen deprivation therapy (ADT) with leuprolide for 18 months presented with new lumbar pain and a prostate-specific antigen (PSA) level that increased from a nadir of $3 \mathrm{ng} /$ $\mathrm{mL}$ to $75 \mathrm{ng} / \mathrm{mL}$ with adequate testosterone suppression. A computed tomography (CT) scan and bone scan showed new bone lesions, without visceral involvement. Therefore, the diagnosis of castration-resistant prostate cancer (CRPC) was made and he started treatment with docetaxel and zoledronic acid with clinical benefit and adequate tolerance. Response evaluation after 6 cycles showed that PSA level decreased to $7 \mathrm{ng} / \mathrm{mL}$ and there was stable disease on imaging.

However, after 9 cycles of docetaxel, the patient complained of pain in his left hip and lumbar spine. Bone scintigraphy confirmed new bone metastases in the left iliac bone. At this time, his PSA level was 63 $\mathrm{ng} / \mathrm{mL}$. He received palliative radiotherapy to the left pelvis and started abiraterone with prednisone. He had symptomatic improvement and a biochemical response with a PSA level of $10 \mathrm{ng} / \mathrm{mL}$.

Six months later, disease progression
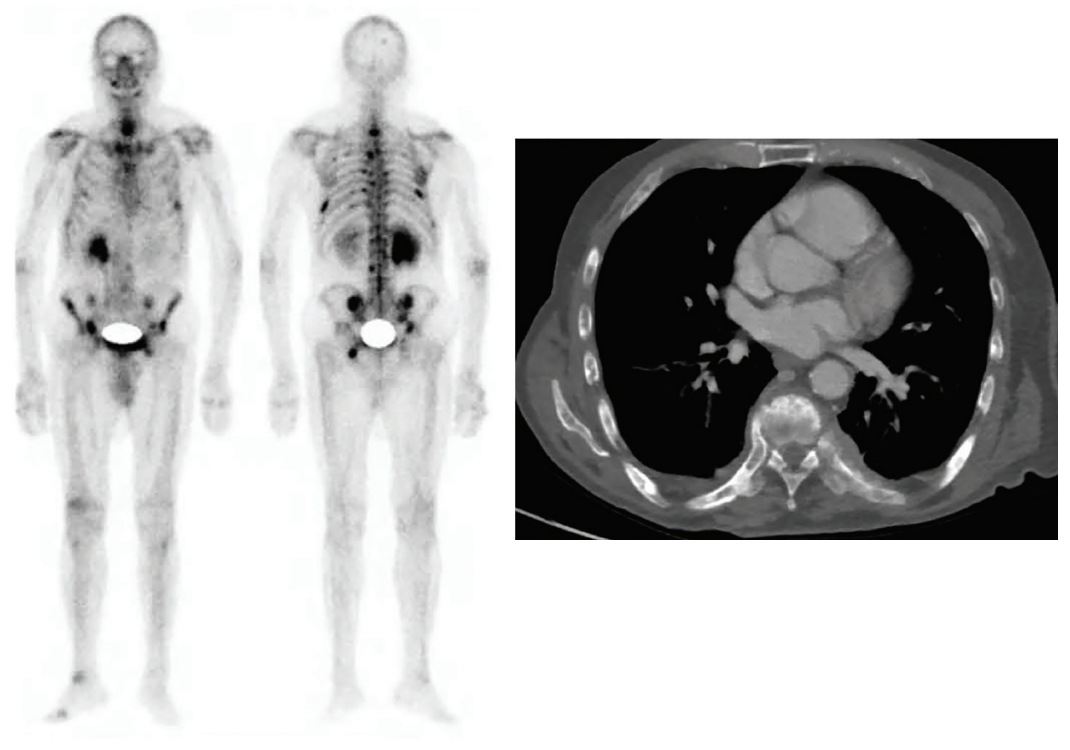

FIGURE 1. A bone scan showed metastases in both iliac crests, the ischium, cervical spine, and ribs (left). A computed tomography scan showed bilateral subpleural nodules consistent with metastatic disease (right).

\section{What is the best treatment option for this patient?}
A. Enzalutamide
D. Radium-223
B. Docetaxel rechallenge
E. Sipuleucel-T
C. Cabazitaxel

TURN TO PAGE 126 for the answer and a discussion of this case by experts. 


\section{CORRECT ANSWER: C. Cabazitaxel improves clinical outcomes in patients with metastatic CRPC (mCRPC) previously treated with docetaxel and an androgen receptor-targeting agent (ARTA).}

Continued from page 125

was documented with a PSA level of 262

$\mathrm{ng} / \mathrm{mL}$, an increase in number of bone

lesions, and new metastatic bilateral sub-

pleural nodules (Figure 1).

\section{Discussion}

Prostate cancer is the second most common malignancy in men and the fifth cause of cancer death worldwide, with an estimate of more than 1.2 million new cases and over 350,000 deaths in $2018 .{ }^{1}$ In the United States, prostate cancer is the most common cancer, comprising $21 \%$ of the new cases of cancer, and the second cause of cancer death, with over 30,000 annual deaths projected for $2020 .^{2}$

ADT with bilateral orchiectomy or a luteinizing hormone-releasing hormone agonist or antagonist has been the backbone of treatment for metastatic castration-naive prostate cancer since the 1940s. ${ }^{3}$ The addition of docetaxel or an androgen rector-targeting agent (ARTA), such as abiraterone or enzalutamide, to ADT has become a standard of care for these patients based on data from randomized phase III trials showing the superiority of combined treatment over ADT alone in terms of overall survival (OS) and progression-free survival (PFS). ${ }^{4-6}$ Selected patients with low-volume disease may also benefit from local treatment with radiation to the primary tumor.

Despite high rates of response, virtually all patients ultimately progress to CRPC in an average time of 2 years after diagnosis. ${ }^{4}$ Over the past few years, several agents have demonstrated improved clinical outcomes in this setting: docetaxel, ${ }^{8}$ cabazitaxel, ${ }^{9}$ abiraterone, ${ }^{10,11}$ enzalutamide, ${ }^{12,13}$ sipuleucel-T, ${ }^{14}$ and radium-223. ${ }^{15}$ These agents can be administered to improve survival, but determining the best sequencing strategy is often challenging because of the scarcity of direct, prospective, randomized comparisons and the movement of many of these agents to use in earlier states of the disease, and cross-resistance between agents.

Sequencing strategies in (mCRPC) are influenced by the choice of first-line treatment which, in the absence of head-to-head comparisons of ARTAs and docetaxel, relies frequently on clinical characteristics of the patient (eg, disease presentation [symptomatic vs mild or asymptomatic], functional status, site of metastases [visceral vs nonvisceral], duration of response to previous treatment, presence of significant comorbidities, toxicity profile of the drug, potential interactions, cost, availability, and patient preferences). ${ }^{16}$

In patients progressing after first-line docetaxel, several drugs have demonstrated improved OS. In the TROPIC trial, cabazitaxel demonstrated an OS of 15 months and a PFS of 2.8 months. ${ }^{9}$ Abiraterone was associated with an OS of 14.8 months and a PFS of 5.6 months in the COU-AA-301 trial. ${ }^{10}$ In the AFFIRM trial, enzalutamide showed an OS of 18.4 months and a PFS of 8.3 months. ${ }^{12}$ These agents have not been compared head to head, so the superiority of one over another cannot be concluded. Choice of therapy is usually made on an individual basis and physician expertise.

The activity of a subsequent hormonal agent in mCRPC is limited after failure to a first-line ARTA. One prospective phase II trial in Canada compared enzalutamide after progression on abiraterone and the reverse sequence. In patients that received second-line enzalutamide after abiraterone, median time to PSA progression was 3.5 months compared with 1.7 months in those receiving second-line abi- raterone after enzalutamide ( $\mathrm{HR}, 0.66 ; P=$ .23) ${ }^{17}$ Both median times to PSA progression were shorter than the 10.2 months recorded in patients treated with abiraterone after docetaxel in the COU-AA-301 trial. ${ }^{10}$

A post hoc analysis from the COUAA-302 trial, in which patients received abiraterone in the first line, PFS was less than 4 months in those who given another ARTA in the second line, ${ }^{18}$ compared with 7.6 months in those given docetaxel in the second line. ${ }^{19}$ In another retrospective cohort of 546 US patients that progressed after first-line therapy with an ARTA, 340 received another ARTA and 206 received a taxane as second-line therapy. The analysis showed that overall response rate (ORR) was greater in the group given chemotherapy compared with the group given an ARTA ( $44 \%$ vs $24 \%$ ), but there was no difference in OS (HR, 0.90). ${ }^{20}$ Therefore, answer A (enzalutamide) may not be the best possible option for this patient since abiraterone was the prior treatment he received.

These findings suggest that the sequential use of ARTAs may lead to a lack of response due to risk of cross-over resistance, whereas docetaxel remains active, although less than when used in the first line. Retreatment with docetaxel after use in the first line has also been described. Retrospective analyses suggest that the efficacy of a rechallenge is associated with the interval between the last cycle of first-line docetaxel-based chemotherapy and progression. Some series report a PFS benefit with a treatment-free interval lasting more than 3 months ${ }^{21,22}$; other investigators suggest that the clinical benefit is reserved for those with a treatment-free interval lasting more than 6 months, without any benefit in OS. Furthermore, prospective data are lacking, and answer B (docetaxel rechallenge) might be best reserved for when there are no other treatments available.

In the third-line setting, a pooled analysis of 13 retrospective studies including 1016 patients evaluated the best treatment sequencing of novel agents (ARTA-ARTA, ARTA-cabazitaxel, and cabazitaxel-AR- 


\section{TABLE 1 Treatment Sequencing Strategies and Clinical Outcomes in mCRPC}

\begin{tabular}{|c|c|c|c|c|c|c|}
\hline Study design & $1^{\text {st }}$ line & $2^{\text {nd }}$ line & $3^{\text {rd }}$ line & ORR, $\%$ & PFS, months & OS, months \\
\hline \multicolumn{7}{|c|}{ Evidence in second line } \\
\hline $\begin{array}{l}\text { Phase II, retrospec- } \\
\text { tive }\end{array}$ & \multirow{2}{*}{ Abiraterone } & Enzalutamide $^{16,17}$ & - & 36 & 3.5 & NA \\
\hline Retrospective & & Docetaxel $^{18}$ & - & 40 & 7.6 & NA \\
\hline Phase II & Enzalutamide & Abiraterone $^{16}$ & - & 4 & 1.7 & NA \\
\hline Phase III & \multirow{3}{*}{ Docetaxel } & Cabazitaxel $^{8}$ & - & 14 & 2.8 & 15 \\
\hline Phase III & & Abiraterone $^{9}$ & - & $38^{\mathrm{a}}$ & 5.6 & 14.8 \\
\hline Phase III & & Enzalutamide $^{11}$ & - & $54^{\mathrm{a}}$ & 8.3 & 18.4 \\
\hline \multicolumn{7}{|c|}{ Evidence in third line } \\
\hline \multirow{3}{*}{ Phase III } & \multirow{3}{*}{ Docetaxel } & \multirow{3}{*}{$\begin{array}{l}\text { Abiraterone or } \\
\text { enzalutamide }\end{array}$} & Cabazitaxel23 & 36 & 8.6 & 13.6 \\
\hline & & & & & & \\
\hline & & & $\begin{array}{l}\text { Enzalutamide or } \\
\text { abiraterone }^{23}\end{array}$ & 11 & 3.7 & 11 \\
\hline \multicolumn{7}{|c|}{ Evidence in second- and further line therapy for patients with somatic alterations in BRCA1/2 or ATM } \\
\hline Phase III & $\begin{array}{l}\text { Initial treat- } \\
\text { ment with } \\
\text { abiraterone or } \\
\text { enzalutamide, } \\
65 \% \text { received } \\
\text { previous tax- } \\
\text { ane therapy }\end{array}$ & Olaparib ${ }^{25}$ & & 33 & 7.3 & $18.5^{\mathrm{b}}$ \\
\hline
\end{tabular}

aProstate-specific antigen response rate.

bInterim results.

mCRPC indicates metastatic castration-resistant prostate cancer; NA, not available; ORR, objective response rate; PFS, progression-free survival; OS, overall survival.

TA) after docetaxel failure; none of these strategies showed clear superiority over another, but a sequence that included cabazitaxel suggested a possible OS advantage. ${ }^{23}$ This was later confirmed in the phase III CARD trial, which randomized 255 patients with mCRPC who progressed in less than 12 months on a prior ARTA, before or after docetaxel therapy, to receive cabazitaxel or the other ARTA (abiraterone or enzalutamide depending on which one was used previously). ${ }^{24}$ The median imaging-based PFS was 8 months with cabazitaxel versus 3.7 months with an ARTA (HR, $0.54 ; P \leq .001)$. Median OS was 13.6 compared with 11 months, respectively ( $\mathrm{HR}, 0.64 ; P=.008)$. The benefit of cabazitaxel was maintained regardless of the sequence of ARTA and docetaxel.
This robust prospective data suggests that cabazitaxel is now the preferred thirdline therapy after docetaxel and 1 ARTA (Table 1). Therefore, answer C (cabazitaxel) is currently the best option for this patient, who has progressive disease after docetaxel and abiraterone.

Radium-223 prolongs OS in chemotherapy naïve (unfit or refusing docetaxel) and docetaxel-treated patients and is approved in $\mathrm{mCRPC}$ with symptomatic bone metastasis without visceral involvement. ${ }^{15}$ Given its mechanism of action, there is no theoretical cross-resistance with taxanes and ARTAs, and it could be used in any line in candidate patients. Concomitant administration of abiraterone and radium-223 is not recommended, as data from the ERA 223 trial showed an increased risk of ad- verse events when both agents were used concurrently. ${ }^{26}$ Answer D (radium-223) is not appropriate because our patient currently has visceral disease.

Sipuleucel-T is an autologous active cellular immunotherapy that has shown to improve OS in MCRPC, with a benefit of 4.1 months compared with placebo. ${ }^{14}$ However, the phase III IMPACT trial excluded patients with visceral metastases, and therefore answer E (sipuleucel-T) would not be suitable for this patient.

One of the key points of sequencing treatment is to understand the mechanism of resistance to therapies. CRPC is not androgen independent and continues to rely on androgen signaling. ${ }^{27}$ Although enzalutamide and abiraterone represent breakthroughs in the treatment of 
mCRPC, approximately $20 \%$ to $40 \%$ of patients have no response to these agents, and among those who initially respond, virtually all will acquire secondary resistance.

One of the most studied mechanisms of resistance is the presence of androgen receptor splice variants (AR-Vs). Antonarakis et $\mathrm{al}^{28}$ demonstrated an association between AR-V 7 (AR-V7) in circulating tumor cells and poor prognosis and resistance to enzalutamide and abiraterone in patients with CRPC. However, in the absence of prospective trials designed to test the predictive value of AR-V7 expression when choosing between taxane- and ARTA-based treatment, its detection only has prognostic value.

Genomic studies have identified another potential driver of resistance in ERG rearrangements that involve genes like TMPRSS2, SLC45A3 and NDRG1 that are transcribed by androgen receptors. ${ }^{16}$ These findings could represent potential therapeutic targets in the future.

CRPC is molecularly heterogeneous, as up to $23 \%$ of mCRPC harbor DNA repair pathway aberrations, and $8 \%$ harbor germline findings.$^{25}$ Loss-of-function alterations in homologous recombination repair genes are associated with a response to poly (ADP-ribose) polymerase inhibition. ${ }^{29}$ The phase III PROfound trial compared olaparib versus enzalutamide or abiraterone in patients with mCRPC with somatic alterations in any of 15 predefined genes with a role in homologous recombination repair whose disease had progressed on a prior ARTA. ${ }^{30}$ Radiologic PFS in cohort A (included alterations in BRCA1, BRCA2, and ATM) was 7.3 months in the olaparib group versus 3.5 months in the control group (HR, $0.43 ; P$ $=.0001$ ), and ORR was $33 \%$ versus $2.3 \%$. OS results are immature, but an interim analysis suggested a benefit with olaparib (HR, 0.64) despite crossover.

Finally, microsatellite instability-high (MSI-high) and mismatch repair deficient (MRD) tumors are found in $2 \%$ to $3 \%$ of patients with mCRPC.25 The immune checkpoint inhibitor pembrolizumab is approved for the treatment of patients with solid tumors that harbor these markers. In a prospective trial carried out at Memorial Sloan Kettering Cancer Center, 11 patients with $\mathrm{mCRPC}$ with MSI-high disease were treated with anti-programmed cell death protein 1 (PD-1) or programmed cell death-ligand 1(PD-L1) therapy. More that $50 \%$ of patients achieved a PSA response and $45 \%$ were still on therapy for up to 89 weeks. ${ }^{31}$ In patients without MSI-high or MRD features, responses to pembrolizumab are more modest. In the phase II KEYNOTE-199 trial that enrolled patients with mCRPC with progression after docetaxel and at least 1 targeted endocrine therapy, ORR was 5\% in PD-L1-positive patients and $3 \%$ in PD-L1-negative patients. Among a third cohort of patients with bone-predominant disease regardless of PD-L1 status, 22\% achieved disease control. ${ }^{32}$ Pembrolizumab is also being studied in combination with other therapies. In a preliminary report from the KEYNOTE-365 trial, pembrolizumab plus olaparib demonstrated a $9 \%$ PSA response rate, a radiographic PFS of 4 months, and an OS of 14 months. ${ }^{33}$

The potential of molecularly targeted treatment in patients with mCRPC highlights the importance of genomic testing in this population. Our patient was advised to be tested to expand his treatment options.

\section{Outcome of This Case}

The patient started treatment with cabazitaxel at $25 \mathrm{mg} / \mathrm{m}^{2}$ every 3 weeks. Currently, he has received 2 cycles of chemotherapy with mild toxicity (grade 1 peripheral neuropathy) and his PSA level decreased more than $50 \%$. A control CT scan and bone scan to evaluate response are pending.

FINANCIAL DISCLOSURE: The authors have no significant financial interest in or other relationship with the manufacturer of any product or provider of any service mentioned in this article..

\section{REFERENCES}

1. International Agency for Research on Cancer. Global Cancer Observatory. International Agency for Research on Cancer website. http://globocan. iarc.fr. Published 2018. Accessed March 30, 2020.

2. American Cancer Society. Cancer Facts \& Figures 2020. American Cancer Society website.. www.cancer.org/content/dam/cancer-org/ research/cancer-facts-and-statistics/annualcancer-facts-and-figures/2020/cancer-factsand-figures-2020.pdf. Published 2020. Accessed March 30, 2020.

3. Huggins C, Hodges CV. Studies on prostatic cancer. I. The effect of castration, of estrogen and of androgen injection on serum phosphatases in metastatic carcinoma of the prostate. Cancer Res. 1941;1(4):293-297

4. Sweeney CJ, Chen YH, Carducci M, et al. Chemohormonal therapy in metastatic hormone-sensitive prostate cancer. N Engl J Med. 2015;373(8):737-746. doi: 10.1056/ NEJMoa1503747.

5. Fizazi K, Tran N, Fein L, et al; LATITUDE Investigators. Abiraterone plus prednisone in metastatic, castration-sensitive prostate cancer. $N$ Engl J Med. 2017;377(4):352-360. doi: 10.1056/ NEJMoa1704174.

6. Davis ID, Martin AJ, Stockler MR, et al; ENZAMET Trial Investigators

and the Australian and New Zealand Urogenital and Prostate Cancer Trials Group. Enzalutamide with standard first-line therapy in metastatic prostate cancer. N Engl J Med. 2019;381(2):121131. doi: 10.1056/NEJMoa1903835.

7. Parker CC, James ND, Brawley CD, et al; Systemic Therapy for Advanced or Metastatic Prostate cancer: Evaluation of Drug Efficacy (STAMPEDE) investigators. Radiotherapy to the primary tumour for newly diagnosed, metastatic prostate cancer (STAMPEDE): a randomized controlled phase 3 trial. Lancet. 2018;392(10162):2353-2366. doi: 10.1016/ S0140-6736(18)32486-3

8. Tannock IF, de Wit R, Berry WR; TAX 327 Investigators. Docetaxel plus prednisone or mitoxantrone plus prednisone for advanced prostate cancer. N Engl J Med. 2004;351(15):1502-1512. doi: 10.1056/ NEJMoa040720

9. de Bono JS, Oudard S, Ozguroglu M, et al ; TROPIC Investigators. Prednisone plus cabazitaxe or mitoxantrone for metastatic castration-resistant prostate cancer progressing after docetaxel treatment: a randomised open-label trial. Lancet. 2010;376(9747):1147-1154. doi: 10.1016/S01406736(10)61389-X.

10. de Bono JS, Logothetis CJ, Molina A, et al; COU-AA-301 Investigators. Abiraterone and increased survival in metastatic prostate cancer. N Engl J Med. 2011;364(21):1995-2005. doi: 10.1056/NEJMoa1014618.

11. Ryan CJ, Smith MR, de Bono JS, et al; COUAA-302 Investigators. Abiraterone in metastatic 
prostate cancer without previous chemotherapy. $N$ Engl J Med. 2013;368(2):138-148. doi: 10.1056/ NEJMoa1209096.

12. Scher HI, Fizazi K, Saad F, et al; AFFIRM Investigators. Increased survival with enzalutamide in prostate cancer after chemotherapy. N Engl J Med. 2012;367(13):1187-1197. doi:10.1056/ NEJMoa1207506.

13. Beer TM, Armstrong AJ, Rathkopf DE, et al; PREVAIL Investigators. Enzalutamide in metastatic prostate cancer before chemotherapy. N Engl J Med. 2014;371(5):424-433. doi: 10.1056/ NEJMoa1405095.

14. Kantoff PW, Higano CS, Shore ND, et al; IMPACT Study Investigators. Sipuleucel-T immunotherapy for castration-resistant prostate cancer. N Engl J Med. 2010;363(5):411-422. doi: 10.1056/NEJMoa1001294.

15. Parker C, Nilsson S, Heinrich D, et al; ALSYMPCA Investigators. Alpha emitter radium-223 and survival in metastatic prostate cancer. N Engl J Med. 2013;369(3):213-223. doi: 10.1056/NEJMoa1213755.

16. Caffo O, Maines F, Kinspergher S, Veccia A, Messina C. Sequencing strategies in the new treatment landscape of prostate cancer. Future Oncol. 2019;15(25):2967-2982. doi: 10.2217/fon2019-0190.

17. Khalaf DJ, Annala M, Taavitsainen S, et al. Optimal sequencing of enzalutamide and abiraterone acetate plus prednisone in metastatic castration-resistant prostate cancer: a multicenter, randomized, open-label, phase 2, crossover trial. Lancet Oncol. 2019;20(12):1730-1739. doi: 10.1016/S1470-2045(19)30688-6.

18. Smith MR, Saad F, Rathkopf DE, et al. Clinical outcomes from androgen signaling-directed therapy after treatment with abiraterone acetate and prednisone in patients with metastatic castration-resistant prostate cancer: post hoc analysis of COU-AA-302. Eur Urol. 2017;72(1);1013. doi: 10.1016/j.eururo.2017.03.007.

19. de Bono JS, Smith MR, Saad F, et al. Subsequent chemotherapy and treatment patterns after abiraterone acetate in patients with metastatic castration-resistant prostate cancer: post hoc analysis of COU-AA-302. Eur Urol. 2017;71(4):656-664. doi: 10.1016/j. eururo.2016.06.033
20. Oh WK, Miao R, Vekeman F, et al. Real-world characteristics and outcomes of patients with metastatic castration-resistant prostate cancer receiving chemotherapy versus androgen receptortargeted therapy after failure of first-line androgen receptor-targeted therapy in the community setting. Clin Genitourin Cancer. 2018;16(1):50-57. doi:10.1016/j.clgc.2017.06.004.

21. Thomas C, Brandt MP, Baldauf $S$, et al. Docetaxel-rechallenge in castration-resistant prostate cancer: defining clinical factors for successful treatment response and improvement in overall survival. Int Urol Nephrol. 2018;50(10):1821-1827. doi: 10.1007/s11255018-1963-1.

22. Loriot $Y$, Massard $C$, Gross-Goupil $M$, et al. The interval from the last cycle of docetaxelbased chemotherapy to progression is associated with the efficacy of subsequent docetaxel in patients with prostate cancer. Eur J Cancer. 2010;46(10):1770-1772. doi: 10.1016/j. ejca.2010.04.010.

23. Maines F, Caffo O, Veccia $A$, et al. Sequencing new agents after docetaxel in patients with metastatic castration-resistant prostate cancer. Crit Rev Oncol Hematol. 2015;96(3):498-506. doi: 10.1016/j.critrevonc.2015.07.013.

24. de Wit R, de Bono J, Sternberg CN, et al. Cabazitaxel versus abiraterone or enzalutamide in metastatic prostate cancer. N Engl J Med. 2019;381(26):2506-2518. doi: 10.1056/ NEJMoa1911206.

25. Robinson D, van Allen DM, Wu YM, et al. Integrative clinical genomics of advanced prostate cancer. Cell. 2015;161(5):1215-1228. doi: 10.1016/j.cell.2015.05.001

26. Smith M, Parker C, Saad F, et al. Addition of radium-223 to abiraterone acetate and prednisone or prednisolone in patients with castration-resistant prostate cancer and bone metastases (ERA 223): a randomised, double-blind, placebo-controlled, phase 3 trial. Lancet Oncol. 2019;20(3):408-419. doi: 10.1016/S1470-2045(18)30860-X.

For full reference list, visit cancernetwork.com/ CRPCQuandary

\section{Key Points}

- The prognosis for patients with mCRPC has improved over the last few years due to the introduction of novel agents.

- The optimal sequence of administering these therapeutic agents remains as a moving target and is not well established. Decisions are usually made according to patients' clinical conditions and disease characteristics, and the safety profile and availability of new drugs.

- Recently, cabazitaxel improved outcomes in the third-line setting after docetaxel and an ARTA. Olaparib is an additional option for second- and thirdline treatment in those with alterations in BRCA1, BRCA2, and ATM.

- Understanding the mechanisms of resistance may provide a rationale for suggesting specific strategies.

- A subset of patients may benefit from molecularly targeted therapies, which highlights the importance of genomic testing in the castration-resistant setting.

- Immunotherapy may provide benefit to some subsets of patients, such as those with MSIhigh tumors. Studies regarding combination therapy with immune checkpoint inhibitors are ongoing.

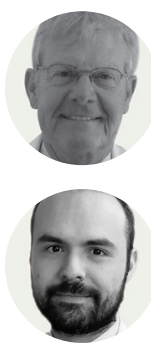

Dr. Crawford is Chairman, Prostate Conditions Education Council; Editor in Chief, Grand Rounds in Urology; and Professor of Urology, University of California San Diego, La Jolla, California.

Dr. Gonzalez-Ochoa is a Medical Oncology Fellow at Instituto Nacional de Ciencias Médicas y Nutrición Salvador Zubirán.
Dr. Bourlon is Associate Professor, Head Urologic Oncology Clinic, National Researcher. Instituto Nacional de Ciencias Médicas y Nutrición Salvador Zubirán. Mexico City, Mexico. She is also a Member of ASCO's IDEA Working Group.

Dr. Verduzco-Aguirre is a Urologic 0ncology Fellow at Instituto Nacional de Ciencias Médicas y Nutrición Salvador Zubirán. 


\section{MEET OUR EXPERT}

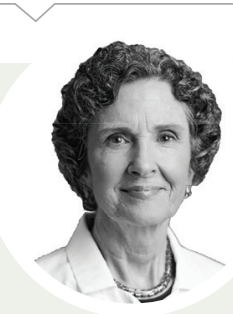

Dr 0'Shaughnessy

is chair of Breast

Cancer Research and

the Celebrating Women

Chair in Breast Cancer at

Baylor-Sammons Cancer

Center, Texas Oncology,

and chair of The US

Oncology Network.

\section{Advancing the Field of Breast Cancer Care}

\section{A "sea change" in treatment}

With the development of immunotherapy and targeted agents, the treatment landscape for patients with breast cancer has evolved immensely, progressing from one-size-fits-all surgeries to the current state of individualized precision medicine. ONCOLOGY ${ }^{\circledR}$ recently sat down with Joyce A. O'Shaughnessy, MD, to discuss the recent trends in breast cancer treatment and the avalanche of agents moving through the development pipeline that have the potential to redefine the accepted standards of care.

Q:

What are the major trends in breast cancer today? Do you think there is an overarching theme that is going to be reflected at the breast cancer conferences this year?

DR O'SHAUGHNESSY: Yes. At all the breast cancer conferences, the novel therapeutics are basically all focused on the molecular drivers of the cancer. For every subtype of breast cancer, there are multiple agents being developed that [target that. So, those are always highlighted because they go hand in hand with... any data on the new agents. Besides that, other things highlighted at the congresses will be advances in immunotherapy for breast cancer. We are kind

\section{PERSPECTIVE}

Natasha Hunter, MD, and Nancy E. Davidson, MD discuss the shifting landscape of targeted therapies page 132

of new in breast cancer in the immunotherapy space, but we do have exciting data emerging, particularly in the curative setting with triple-negative breast cancer. We also have a new approval in the metastatic setting for triple-negative breast cancer that is programmed cell death protein-ligand 1-positive with atezolizumab (Tecentriq). Everybody is keenly interested in checkpoint inhibitor therapy in the breast cancer space. At all of our congresses, we also highlight locoregional control. There is a trend towards doing less surgery over time, and probably radiation therapy has become a bit more comprehensive for the high-risk patients, but [it is a] shorter course. And even more limited is partial breast irradiation, not whole breast irradiation for lower risk patients. Radiation therapy is becoming personalized. The surgery is becoming personalized. So, we spend a lot of time, because those are very rapidly evolving areas, in locoregional control.

1. "When you talk about surgery," are you referring to the trend toward neoadjuvant therapy to see if tumors can be shrunk instead of surgically removed?

DR O'SHAUGHNESSY: Yes, and so [we are] able to do a lumpectomy instead of a mastectomy because [we] shrunk [the tumor] down, but also less axillary surgery which is very important. [We are] taking out fewer axillary lymph nodes and decreasing the risk of lymphedema.

Q:

What are some of - the more important recent treatment breakthroughs, and which studies in particular are you looking forward to learning about or hearing about this year?

DR O'SHAUGHNESSY: We just recently had the FDA approval [of trastuzumab deruxtecan (Enhertu)], and a lot of these data came out at [the] San Antonio [Breast Cancer Symposium]. All these [results] are so new that it is very important to have our congresses to help 
bring clinicians up to speed on the data.

We [can also] expect FDA approval very soon of the oral HER2 tyrosine kinase inhibitor, tucatinib, and for metastatic breast cancer, oral neratinib (Nerlynx). We already have neratinib approved in the extended adjuvant setting for patients with HER2-positive breast cancer. Now we are waiting for neratinib to be approved in the metastatic setting. Hope[fully] later this year we will see approval by the FDA [for margetuximab], another agent for HER2-positive breast cancer, a molecularly enhanced form of trastuzumab.

With regard to triple-negative breast cancer, we are looking forward, we hope, to the FDA approval of the antibody-drug conjugate, sacituzumab. We are waiting for that. Then we are really keeping our fingers crossed, crossed, crossed.

We will have to see what additional data show, but we are keeping our fingers crossed for the preoperative pembrolizumab (Keytruda) trial [KEYNOTE-522] in triple-negative breast cancer to continue with further follow-up [and demonstrate] improvement in event-free survival. [If so, it] should lead to FDA approval.

The other thing [that] we are waiting for [are data from]

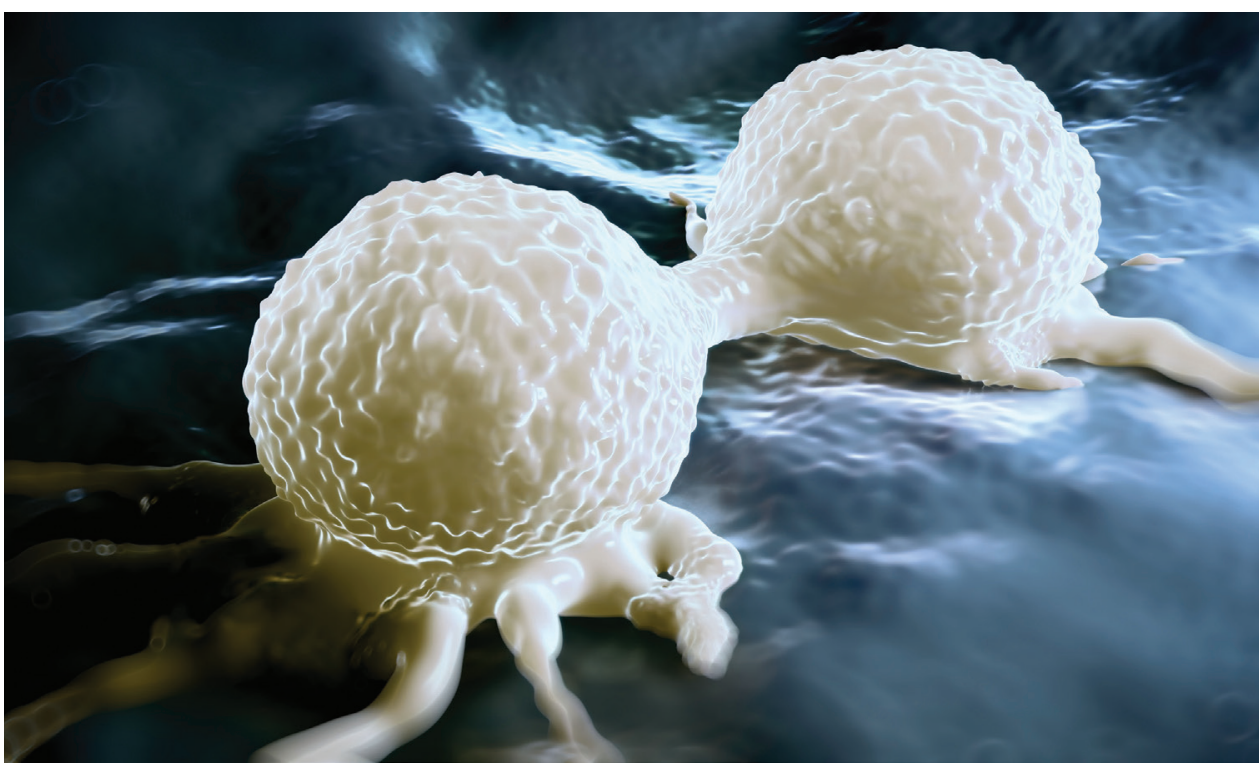

Dividing breast cancer cell.

some of the adjuvant cyclin-dependent kinase (CDK) 4/6 inhibitor trials...in [patients with] high-risk, estrogen receptor (ER)-positive breast cancer, such as the PENELOPE-B trial which...should [have results] later this year. [In that trial,] With regard to patients with ER-positive triple-negative breast cancer breast cancer, received preoperative [chemotherapy], they still have residual disease at surgery, then they [were given] endocrine therapy, and [finally,] they were randomized to receive 1 year of palbociclib or placebo. [Data] should be [available] soon. [Data are expected from] a couple of other adjuvant CDK4/6 inhibitor trials... within the next year, we hope. That could lead to FDA approvals of CDK4/6 inhibitors in the curative setting, which will be very exciting.

\section{Do you believe 1. that a lot of the recent progress has to do with gaining a better understanding of the molecular mechanisms behind breast cancer?}

DR O'SHAUGHNESSY: Yes, and being able to choose the right patient populations. You could have a great agent, but if you do not choose the right patient population, it [will not] have the level of effectiveness it needs [to be granted] FDA approval.

\section{Q:} On the community level, is matching treatments and sequencing tumors widespread or is it an area that still requires more education?

DR O'SHAUGHNESSY: We have had a sea change in breast cancer just within the last 6 months with the FDA approval of alpelisib (Piqray). It is the first PI3K alpha-specific inhibitor. [However,] it is for ER-positive breast cancers that have the PIK3CA mutation, and that is about $40 \%$ of ER-positive breast cancers. And it is for [patients with] metastatic [disease]. So, you have...to now go looking [for the mutations]. You have...to sequence the breast cancer. You can also get circulating tumor DNA [through] a blood test, because many times you will find the PIK3CA mutation in the blood or in the tumor. For the first time, we have a definite reason for [patients with] ER-positive metastatic [breast cancer] to get next-generation sequencing (NGS).

The FDA approved pembrolizumab for patients with mismatch repair deficient or microsatellite instability-high breast cancers. [That is] only about $2 \%$ of breast 


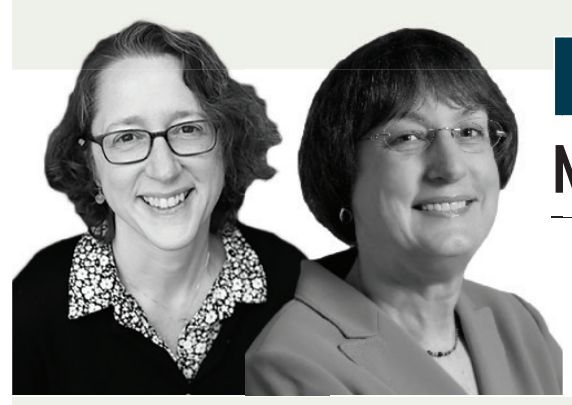

$\mathrm{T}$ argeted therapies have traditionally played a huge role in breast cancer treatment, and this will only increase. As we learn more about molecular mechanisms of breast cancer, matching the right agent with the right patient will be key, as Dr O'Shaughnessy points out. This will require excellent biomarkers, more consistent ways to obtain metastatic samples, and methods to achieve continuous surveillance for nimble-and even anticipatory-responses to tumor evolution and resistance. It also means that the world of breast cancer care will become increasingly complex for providers, raising the question of how to disseminate this burgeoning body of knowledge to all clinicians.

Dr O'Shaughnessy discusses how the FDA approval of alpelisib (Piqray) is bringing a sea change in metastatic breast cancer. As $40 \%$ of estrogen receptor-positive (ER-positive) tumors demonstrate PIK3CA mutations, molecular analysis of metastatic tissue has suddenly become critical in the clinical management of patients with metastatic breast cancer. As investigators develop even more targeted agents, obtaining metastatic specimenspossibly in a serial fashion through liquid biopsy-will likely become routine.

But what will we measure? We all agree that accurate and validated biomarkers are essential, but this area is in tremendous flux, even with more standard markers. For example, several new agents have emerged in the human epidermal growth factor receptor 2 (HER2) space. Trastuzumab deruxtecan (Enhertu) demonstrates striking activity

\section{Natasha Hunter, MD, and Nancy E. Davidson, MD} The Changing Landscape of Targeted Breast Cancer Therapies

in HER2 low-expressing, ER-positive breast cancer; in an era where we see more "splitting" than "lumping" in targeted therapies, it is encouraging to witness a drug that may enjoy a broader application across breast cancer histologies. ${ }^{1}$ Results from the recent SUMMIT basket trial evaluating patients with classically HER2-negative tumors suggest that patients whose tumors display $E R B B 2$-activating mutations may benefit from the oral agent neratinib (Nerlynx). ${ }^{2}$ Although the American Society of Clinical Oncology/College of American Pathologists HER2 practice guideline update released

\section{We all agree that accurate} and validated biomarkers are essential, but this area is in tremendous flux, even with more standard markers

in 2018 addressed several ambiguities for clinical decision making. ${ }^{3}$ Such developments underscore that the $H E R 2$ pathway remains a fertile area of investigation. Indeed, we may move beyond classifying tumors as simply HER2-positive or HER2-negative.

We face similar challenges with newer biomarkers. Given the results of KEYNOTE-522, we are likely to see FDA approval of pembrolizumab (Keytruda) in the neoadjuvant setting for triple-negative breast cancer (TNBC) in the coming year. But the KEYNOTE investigators (including Dr O'Shaughnessy) point out the difficulty in understanding differ- ences in patient response based on programmed cell death protein 1 expression when they are uncertain how to define this metric. ${ }^{4}$ The androgen receptor (AR) is another exciting target in breast cancer therapeutics, but the definition of AR positivity remains a question. Sensitivity to Akt inhibitors such as ipatasertib may be indicated by PTEN loss, and markers that we do not currently test, such as Akt phosphorylation. Rapid and careful basic and translational research will be key to elucidate the signals that best indicate the activity of these drugs in our patients.

Of course, the utility of a biomarker is inextricably tied to its interpretation and context. The same genomic mutation may support very different avenues of therapy, given different breast tumor histologies or multiple possible therapies for the same histology. The Akt inhibitors, which Dr O'Shaughnessy predicts may soon enter practice in breast cancer, offer an example. Ipatasertib, a potent Akt inhibitor under investigation in breast, prostate, and other solid tumors, seems to demonstrate synergistic activity with chemotherapeutic agents such as paclitaxel through activation of the $\mathrm{PI} 3 \mathrm{~K} /$ Akt pathway in the setting of mitotic stress in a tumor. Patients whose triple-negative breast tumors demonstrated alterations in PIKЗCA, Akt1, or PTEN in next-generation sequencing (NGS) assays appear to derive the most benefit from the addition of this drug in early analyses. ${ }^{5,6}$ Capivasertib has also shown a similarly stratified response among patients with TNBC with and without

Perspective continued on page 134 
cancers, but nonetheless, they can do very, very well with this immune-based therapy. Then the FDA approved the neurotrophic tyrosine kinase (NTRK) inhibitors-[larotrectinib (Vitrakvi) and entrectinib (Rozlytrek)]. [They are] for any cancer. It's a tumor agnostic approval that has an NTRK fusion at the genomic level... a gene fusion. And, again, rare in breast cancer, [approximately] $1 \%$, but if [a patient has] it, you can do NGS to find the NTRK fusion, [the] microsatellite instability, and [the] PIK3CA mutations.

In breast cancer,... we have had a reason to do germline testing, blood [tests] looking for BRCA1 and 2, since the FDA approved the 2 poly (ADP-ribose) polymerase (PARP) inhibitors that we have for patients with germline BRCA1 and 2. So, we have been doing germline genetic testing because in the metastatic setting, we have...2 PARP inhibitors. So, the whole [NGS] thing is really gaining traction in breast cancer.

\section{How many agents 1: do you anticipate being approved in the breast cancer space this year, and perhaps over the next year or 2 as well?}

DR O'SHAUGHNESSY: [I]n the metastatic setting, we are expecting sacituzumab, tucatinib, neratinib, and margetuximab this year. And then hopefully preoperative pembrolizumab. That is a little bit aspirational, but the data [to facilitate approval] should be there. The data look good, they just have to hold up. So, I will say pembrolizumab this year. And then next year, I...hope we have another antibody-drug conjugate called SYD985, which is another anti-HER2based therapy. I am hoping we are going to have adjuvant palbociclib (Ibrance) and adjuvant abemaciclib (Verzenio). Ribociclib (Kisqali) will take another year or 2 thereafter.

Within 2 years, we might have adjuvants. We hope capivasertib, [and the other] Akt inhibitors. [Although it may] be more like 2022...the Akt inhibitor capivasertib by AstraZeneca, and ipatasertib by Genentech Roche, [which] are in active development, [may be available for]... ER-positive breast cancer [and] triple-negative breast cancer.

Hopefully [we will have] some of the oral selective ER degraders in ER-positive [breast cancer]. There is one called elacestrant that is in [a] phase III [trial] right now,... the EMERALD trial, and maybe by [the end of] 2020 we will have [data]. One I really do hope we have next year is the oral taxane, tesetaxel, by a company called Odonate. Now, there were data... at San Antonio [Breast Cancer Conference], and the study was not done in the United States, but it was a very positive trial. It is called OPE. It is oral paclitaxel with encequidar, which basically allows the [taxane] to be absorbed into the bloodstream from the gastrointestinal tract. It is an oral taxane by a company called Athenex. The data looked very good. I hope it will lead to [an] FDA approval. It may be later this year, [or] it could be next year.

An important new area... is with trastuzumab deruxte-

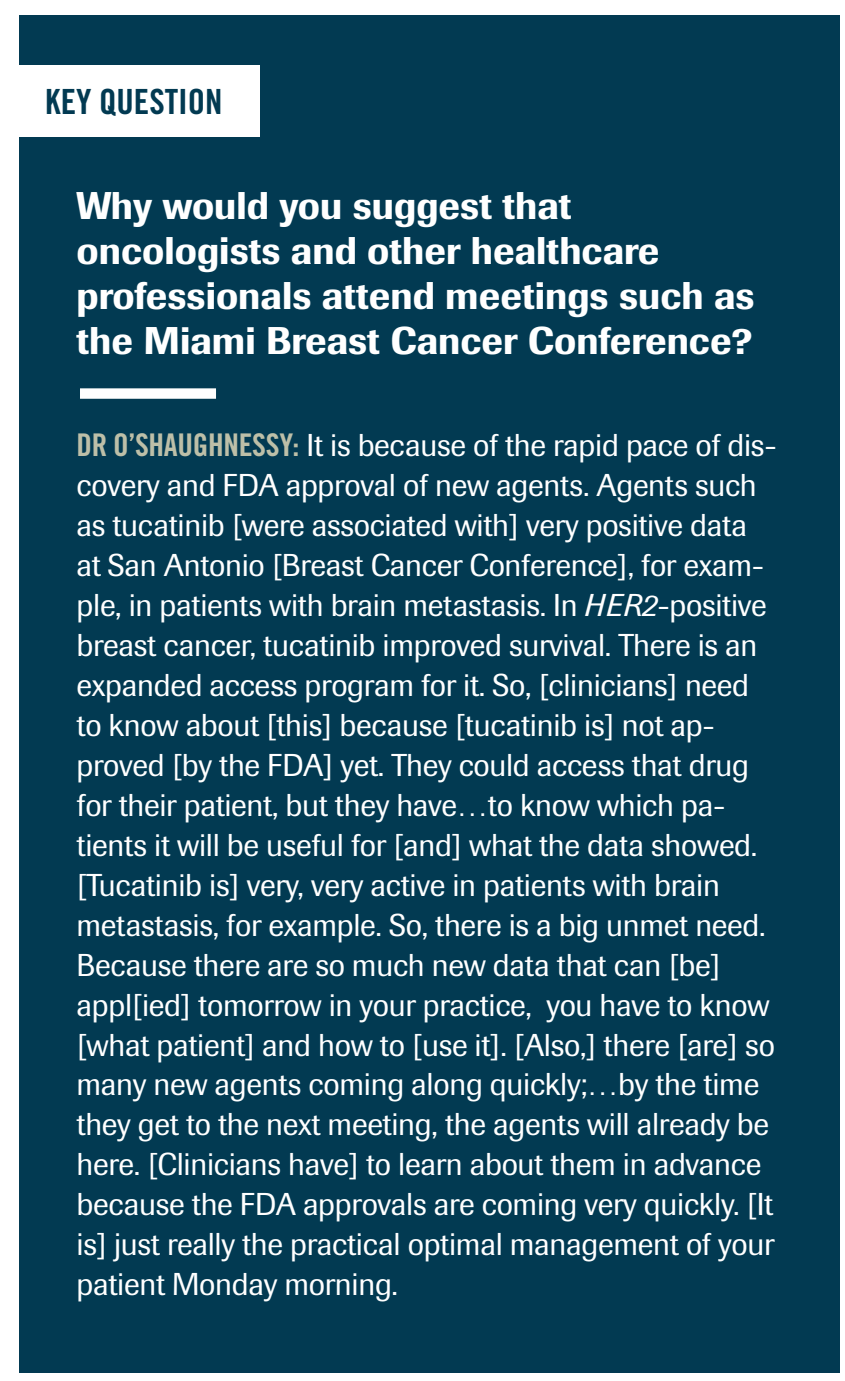

can. It was just approved by the FDA for HER2-positive breast cancer. A very, very important...new strategy is [when the] antibody against HER2 [is] hooked up to this powerful chemotherapy drug, deruxtecan. It can bind to breast cancers, particularly ER-positive breast cancers that...have a low level of HER2. So, they are really not HER2-positive, but they [have] some HER2 protein and [the drug is] looking really, really active. It is being compared in phase III trials with [physician's choice of] chemotherapy and [results could] redefine the subtypes of breast cancer. [With] HER2-positive,... [there is] HER2 amplification, lots of gene copies. But then [there is] this HER2-low, low positive, and that is where...we do not have [agents] right now. So that would be very, very exciting. I suppose that [this strategy] could be with us in 2022. These are my sort of broad estimates based on how quickly I think the studies will accrue [data] and the ones I think are going to be positive.

The other is the atezoli- 


\section{Natasha Hunter, MD, and Nancy E. Davidson, MD}

\author{
PERSPECTIVE CONTINUED FROM PAGE 132
}

these mutations. ${ }^{7}$

Meanwhile, preliminary results

from a phase IB study investigating ipatasertib, atezolizumab (Tecentriq), and paclitaxel versus nab-paclitaxel (Abraxane) for locally advanced or metastatic TNBC showed an overall response rate of $73 \%$ regardless of biomarker status. ${ }^{8}$ One projected mechanism for this response is downregulation of Akt, which is thought to potentiate resistance to immune checkpoint inhibition. Antagonizing the PI3K/ Akt pathway may reverse this resistance and prolong response to immunotherapy. ${ }^{9}$

If both therapeutic pathways ultimately demonstrate benefit, it may be difficult to determine which therapy to choose in a patient with the relevant mutation(s). This is a "good" dilemma, but one we will likely face repeatedly as other targeted drugs enter the pipeline. Additional hurdles include optimizing drug combinations, which have often been limited by toxicity, and questions of sequencing and prioritizing therapies. Further research should clarify these and other issues over time, but the entire field will change and develop rapidly for the foreseeable future.

In the face of such complexities, medical oncologists will need to seek out educational opportunities to stay abreast of a rapidly changing field. Traditionally, meetings like Miami Breast Cancer Conference ${ }^{\circledR}$ have offered updates. In the era of coronavirus disease 2019 and beyond, more virtual seminars and conferences may supplant large in-person gatherings. But even this may not be enough. In the same way that today's hospital would not purchase a positron emission tomography (PET) scanner without hiring a radiologist who can interpret PET images, we soon may consider molecular testing reports to be of limited utility without access to high-level clinical expertise in molecular pathology and biomarker interpretation. Practices across the country are already making use of molecular tumor boards to parse the complex information offered by NGS reports. With the emergence of new drugs and novel postgenomic biomarkers, including functional protein assays, RNA testing, and epigenetic profiling, the demand for this vital specialized assistance will only increase.

We live in an exciting and hopeful era for breast cancer therapeutics; however, advances bring challenges in matching the right therapy to the right patient at the right time. Validated biomarkers are needed along with investigations into how to best translate our new knowledge into therapeutic interventions. Clinicians must continuously educate themselves as they adjust to this shifting landscape; however, they will also need guidance in the form of strong ties to specialist molecular pathologists and tumor boards.

$\rightarrow$ For references visit cancernetwork.com/BCTherapies
Dr. Hunter is an Assistant Professor of Oncology in the breast oncology group at the University of Washington. Her research interests include circulating tumor DNA and clinical biomarker development.

Dr. Davidson serves as President of the Seattle Cancer Care Alliance, Senior Vice President and Director of the Clinical Research Division of the Fred Hutchinson Cancer Research Center, and Chief of the Division of Medical Oncology at the University of Washington. She served as President of the American Society of Clinical Oncology from 2007-2008 and President of the American Association of Cancer Research from 2016-2017. zumab, the competitor basically to pembrolizumab. Atezolizumab is already approved for triple-negative [breast cancer] in the metastatic setting. It too is in preoperative studies in triple-negative breast cancer. I hope [it will] be approved [by the FDA for this indication]. We are waiting on the data to be released, but hopefully [it] will be approved in 2021 . We also hope that pembrolizumab, will be approved in 2021 for patients with metastatic breast cancer. So, we are waiting for pembrolizumab for both metastatic triple-negative and then most importantly, in the curative setting preoperatively.

\section{. I know that patients, 1. obviously, are a big part of what continues to drive your interest in research. But putting it into practice, are there any patient cases that particularly jump out at you or any particular experience that you had with a patient that was really rewarding?}

DR O'SHAUGHNESSY: Thankfully a lot of them, because I actually have a strong interest in the area of exceptional responders. These are [patients with] metastatic breast cancer that basically go on to... get cured or they just do well for 5 or more years. Those [patients] are extremely gratifying because they are not expected. [W] hen somebody develops metastatic triple-negative breast cancer, the median lifespan is about 16 months. So, when somebody gets cured, you are standing up, you are doing cartwheels, big-time cartwheels. [Therefore], I have a strong interest in trying to understand the molecular basis for why a particular breast cancer would [be] so responsive, so unexpectedly responsive to...treatment. I have a number of those exceptional responders that are just absolutely fascinating to me, [and it is] extremely gratifying to take care of... patients. I have...a number of stories in that regard. you could share? 
DR O'SHAUGHNESSY: Because this woman basically has directed a lot of my subsequent research, and she does not mind me using her name. Her first name is Donna. She does not mind because she has...done videos for our fundraising activities around clinical trials to follow up on her success, etcetera. She was diagnosed in 2006 I think, [she] was in her mid-50s, with triple-negative breast cancer, and [she] had [a] lumpectomy,...chemotherapy, and radiation therapy. Her breast cancer recurred in 2008 in her breast. It was node-positive. She had a mastectomy. She had axillary dissection. She had more chemotherapy. She

I have a number
of those
exceptional
responders
that are just
absolutely
fascinating
to me, [and it
is] extremely
gratifying to
take care of...
patients.

had more radiation therapy.

Between 2008 and 2011 (when I first met her), she had multiple recurrences, locoregionally on the chest wall, in the supraclavicular, infraclavicular lymph node

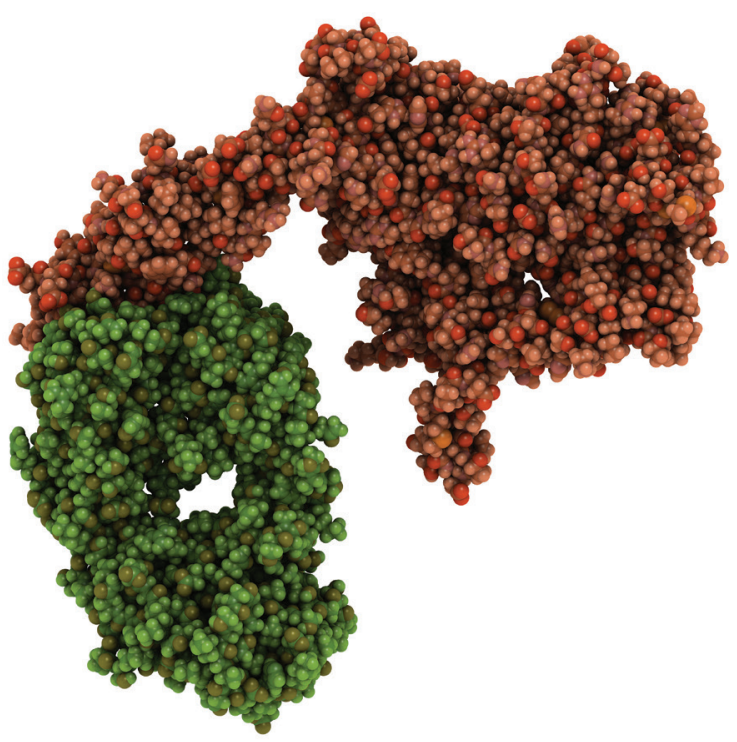

Chemical structure of the extracellular part of HER2 with a fragment of trastuzumab bound.

beds, [and in the] subpectoral [lymph node beds]. But it was only [in the] lymph node[s], nowhere else. She kept having multiple surgeries, targeted radiation therapy, and more and more chemotherapy. So, she had had all our major chemotherapy agents for triple-negative breast cancer, including taxanes and carboplatin, etcetera. But the disease just kept recurring. It was not very fast, but it kept recurring.

I met her in 2011 when she came over from UT Southwestern for a clinical trial that we had, and she had [the disease in] a left supraclavicular lymph node. It was about $3 \mathrm{~cm}$ in size and that was the only disease she had. So, we biopsied it. We did next-gen[eration] sequencing, and we did not find any particular mutation to go after except that she [had] a FOXM1 amplicon, and... somatic loss of function mutations in SMARCA4 (which among other things...is part of the SWI/SNF family of proteins that are very involved in DNA repair, double-strand DNA repair).

She happened to go on to a clinical trial, a single-agent trial of an agent called BEZ235 (dactolisib) which is a PI3K inhibitor, a target of rapamycin complex (TORC) 1 , TORC2 inhibitor, and it also inhibits DNA repair. So, her cancer...respond[ed] to that. Her left supraclavicular lymph node went from $3 \mathrm{~cm}$ down to $1.5 \mathrm{~cm}$, but, [it] was a short-lived response. After about 6 weeks on therapy, she responded and then the left supraclavicular lymph node started growing very, very quickly which is unusual because it had been pretty slow. So that was resected.

A few months later, she came in again and a computed tomography scan showed some pectoral lymph node [growth] but that was all she had. Again, that was resected. All she had was [a] resection. When she recovered from that surgery, [the] subpectoral lymph node, she came [back] in January 2012. She had very, very rapidly growing internal mammary lymph nodes and some of it was substernal underneath the sternum. It was growing [so] fast that it was bowing out her sternum. It was not eroding. The cancer was not eroding through her sternum, but it was pushing the sternum out. The sternum is flat. It was being bowed out [because the tumor] was growing so fast, and she was in pain. So, big, big nodal disease. And so very fast. I treated her with [high-dose] nab-paclitaxel (Abraxane) and cisplatin every 3 weeks. She [received] 6 cycles. She was in a complete response after 2 cycles and...is cured. Her disease never came back. And so, I have tissue all along the way, all the biopsies. She had biopsies. She had multiple surgeries. I have done a lot of analysis of the molecular characteristics and also the reverse phase protein 
array...which is the protein expression...the activation of proteins in her breast cancer. I really think that...the BEZ235 remodeled her cancer. It got rid of the signaling through the PI3K pathway. It inhibited DNA-dependent protein kinase, and it basically [made] her cancer shift over to a highly proliferative mitogen-activated protein kinase, mitogen-activated protein kinase kinase/extracellular signal-regulated kinase-driven breast cancer. It reexposed the homologous recombination deficiency in her breast cancer which we think [was] there because [of] the SMARCA4 loss of function deletion.

So, it made her cancer much more sensitive to chemotherapy, DNA-damaging chemotherapy, such as the cisplatin. Also, [it was] so fast growing that the nab-paclitaxel stopped [the] fast growing cancer cells, too. It made her cancer exquisitely sensitive to chemotherapy even though she never benefitted from chemotherapy before. I think the BEZ235 changed the nature of that cancer and made it much more chemotherapy sensitive, more BRCA like. These kinds of trials are called priming the breast cancer, priming it to make it more...BRCA like, basically. So, that shifted the direction of my pilot trial, my translational research that I do on my own, doing... biopsies and such, trying to recapitulate, try[ing] to repeat that in other patients.

Q: That is a remarkable case.

DR O'SHAUGHNESSY: Oh yeah.

\section{I really think that...the BEZ235 remodeled her cancer. It got rid of the signaling through the PI3K pathway. It inhibited DNA-dependent protein kinase, and it basically [made] her cancer shift over to a highly proliferative mitogen-activated protein kinase, mitogen-activated protein kinase kinase/extracellular signal-regulated kinase-driven breast cancer.}

\section{Q:}

What should receive more emphasis in the discussion and clinical attention among oncologists today in your field? What should be emphasized more overall? DR O'SHAUGHNESSY: Well, so where we really need help is with insurance coverage or national guidelines and insurance coverage for our patients who are obese or who are obese at diagnosis or who become obese during their breast cancer journey. Many of our therapies slow patients' metabolic rates because it puts them into a deeper menopause, [the] antiestrogen therapies. Some of the therapies make patients fatigued and so they are less active. But many of our [patients with] ER-positive [breast cancer] on...aromatase inhibitors... gain weight. A...weight gain [of $10 \%$ or more] in women with ER-positive breast cancers increases the risk of breast cancer recurrence. And [if a patient has] node-positive disease, [it] can happen 20 years later. We know [that] our obese patients, in general, not $100 \%, \ldots$ have less favorable outcomes, [poorer] outcomes with our therapies.

We know from studies like...WINS... (Women's Intervention Nutrition Study) by Rowan Chlebowski [et al],...that in ER-negative breast cancer,...a low-fat diet, which was associated with a modest weight loss, $5 \%$ weight loss, made a big difference in decreasing the risk of recurrence. We do not know whether it was the lowfat diet, or...the weight loss, but we are pretty desperate for structured approaches. [We need] structured approaches that will be supported by insurance for weight loss and to increase the fitness of our patients with exercise. That is the big, big thing we are lacking.

\section{Q: Can you expand on what you mean by structured programs?}

DR O'SHAUGHNESSY: By structure, I mean things that women are expected to show up to, like [a] meeting with the nutritional counselor or weekly meetings in groups to support each other through weight loss. [Other examples include]...programs that might pay for parking,...gas,... [or] the instructor, [and] exercise programs that are covered. Or, paying for [a] YMCA membership, covering the classes and then having classes for survivors, etcetera, but real structure. A lot of it [centers] around community, having a community to walk this journey with. But you cannot [just] tell people to diet and eat healthy and exercise. It does not help people.

\section{Q:}

Is there anything else that you wanted to discuss?

DR O'SHAUGHNESSY: I always like to plug my School of Breast Oncology®. It's a 3-day, deep dive breast cancer boot camp. Soup to nuts, all the important literature in breast cancer but [it is] very practical. It is all case-based discussion for the surgical oncologist, medical oncologist, [and] radiation oncologist to come and really get a very in-depth update on all of the key data around [the] management strategies for breast cancer, including breast cancer prevention, genetic germline evaluation, [etcetera]. What are the data [surrounding] diet and exercise? What about breast cancer in pregnancy? What about toxicity management? [All questions with a] big emphasis on radiation and surgical issues. So, a big, multidisciplinary course.

\section{FINANCIAL DISCLOSURE:}

The authors have no significant financial interest in or other relationship with the manufacturer of any product or provider of any service mentioned in this article. 


\section{FDA Approves Nivolumab Plus Ipilimumab for the Treatment of Advanced HCC}

Kevin Wright

$\mathbf{T}$ he FDA granted accelerated approval for the combination use of nivolumab (Opdivo) plus ipilimumab (Yervoy) for the treatment of patients with hepatocellular carcinoma (HCC) who received prior treatment with sorafenib (Nexavar). ${ }^{1}$ The agency's approval is based on cohort findings from the phase I/ II CheckMate-040 trial (NCT01658878), which demonstrated an objective response rate (ORR) of $33 \%$ (95\% CI, 20-48) in patients who received the nivolumab and ipilimumab combination.

At a median follow-up of 28 months, 16 of $49(33 \%)$ patients responded to treatment, with $4(8 \%)$ experiencing a complete response (CR), and $12(24 \%)$ demonstrating a partial response (PR). Additionally, the duration of response (DOR) ranged from 4.6 to $30.5+$ months, with $88 \%$ of responses lasting at least 6 months, $56 \%$ lasting at least 12 months, and $31 \%$ of responses lasting 24 months or longer. Blinded independent central review (BICR) using modified Response Evaluation Criteria in Solid Tumors (RECIST) assessed ORR at 35\% $(95 \% \mathrm{CI}$, 22-50), with a CR reported in $12 \%$ of patients and a PR reported in $22 \%$.

The FDA granted the approval on March 10, 2020, at a dose of $1 \mathrm{mg} / \mathrm{kg}$ of nivolumab and $3 \mathrm{mg} / \mathrm{kg}$ of ipilimumab. The treatment becomes the only dual immunotherapy approved by the FDA in this setting.

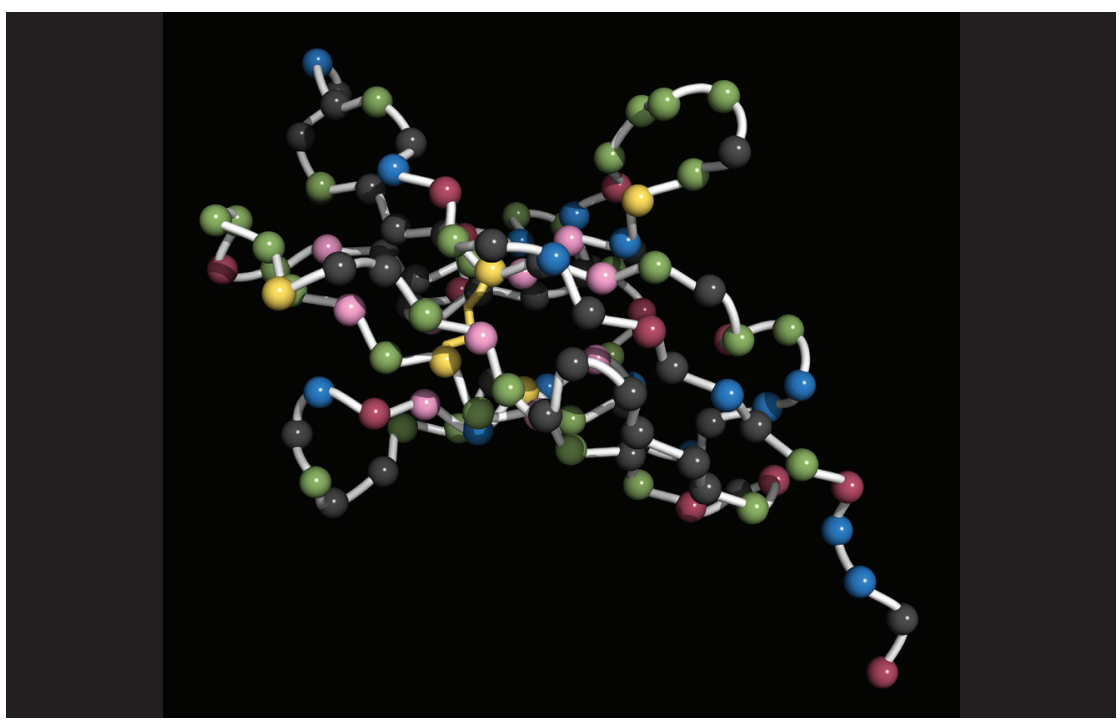

- Programmed cell death 1 (PD-1, CD279) receptor protein.

"HCC is an aggressive disease in need of different treatment approaches," said Anthony B. El-Khoueiry, MD, lead investigator and associate professor of clinical medicine and phase I program director at the Keck School of Medicine, University of Southern California (USC) and the USC Norris Comprehensive Cancer Center, in a statement. "The ORR observed in the Opdivo plus Yervoy cohort of the CheckMate-040 trial underscores the potential of this dual immunotherapy as a possible treatment option for patients."

Patients were randomized 1:1:1 to one of 3 dosing schedules with the com- bination, and treatment continued until unacceptable intolerability or disease progression. Arm A ( $\mathrm{n}=50)$ was given $1 \mathrm{mg} /$ $\mathrm{kg}$ of nivolumab plus $3 \mathrm{mg} / \mathrm{kg}$ of ipilimumab every 3 weeks for 4 cycles, arm B $(\mathrm{n}=49)$ was given $3 \mathrm{mg} / \mathrm{kg}$ of nivolumab plus $1 \mathrm{mg} / \mathrm{kg}$ of ipilimumab every 3 weeks for 4 cycles, and arm $C(n=49)$ received nivolumab at $3 \mathrm{mg} / \mathrm{kg}$ every 2 weeks plus ipilimumab at $1 \mathrm{mg} / \mathrm{kg}$ every 6 weeks. Patients in arms A and B were then given a flat dose of nivolumab $240 \mathrm{mg}$ intravenously every 2 weeks. ${ }^{2}$

The majority of patients in all 3 arms (A, $88 \%$; B, $85 \%$; C, $79 \%)$ had 
discontinued sorafenib due to disease progression. Primary end points of the trial included safety and tolerability; key secondary end points were ORR (BICR per RECIST v1.1), DOR, and overall survival.

Serious adverse events (AEs) occurred in $59 \%$ of patients receiving the combination; treatment was discontinued in $29 \%$ of patients and delayed in $65 \%$ of patients experiencing an AE. Serious AEs reported in at least $4 \%$ of patients were pyrexia, diarrhea, anemia, increased aspartate aminotransferase, adrenal insufficiency, ascites, esophageal varices hemorrhage, hyponatremia, increased blood bilirubin, and pneumonitis. The most common adverse reactions (reported in $\geq 20 \%$ of patients) were rash $(53 \%)$, pruritus $(53 \%)$, musculoskeletal pain $(41 \%)$, diarrhea $(39 \%)$, cough $(37 \%)$, decreased appetite $(35 \%)$, fa- tigue $(27 \%)$, pyrexia $(27 \%)$, abdominal pain $(22 \%)$, headache $(22 \%)$, nausea $(20 \%)$, dizziness $(20 \%)$, hypothyroidism $(20 \%)$, and weight decreased $(20 \%)$.

Since 1980, liver cancer incidence rates have more than tripled, with an estimated 42,810 new cases expected to be diagnosed in 2020. Death rates have more than doubled in the same time period. ${ }^{3}$

"The incidence of liver cancer is rising in the United States, and HCC is the most common and aggressive form of the disease," a spokesperson from Bristol Myers Squibb told ONCOLOGY®. "Patients with advanced HCC who relapse on firstline therapy are in need of new options."

Continued approval for this indication is contingent upon verification and description of clinical benefit in confirmatory trials.

FINANCIAL DISCLOSURE: The authors have no significant financial interest in or other relationship with the manufacturer of any product or provider of any service mentioned in this article.

\section{REFERENCES}

1. U.S. Food and Drug Administration approves Opdivo (nivolumab) + Yervoy (ipilimumab) for patients with hepatocellular carcinoma (HCC) previously treated with sorafenib [news release] Princeton, NJ: Bristol Myers Squibb; March 11, 2020. https://news.bms.com/press-release/ corporatefinancial-news/us-food-and-drugadministration-approves-opdivo-nivolumab-ye-0. Accessed April 2, 2020.

2. El-Khoueiry AB, Hsu C, Kang YK, et al. Safety profile of nivolumab (NIVO) plus ipilimumab (IPI) combination therapy in patients with advanced hepatocellular carcinoma (HCC) in the CheckMate 40 study. Presented at: 13th Annual Conference of the International Liver Cancer Association; September 20-22, 2019; Chicago, IL. Abstract O-13. ilca-online.org/wp-content/ uploads/2019/09/ABSTRACTS-2019-min.pdf.

3. American Cancer Society. Key Statistics About Liver Cancer. American Cancer Society website. https://uww.cancer.org/cancer/liver-cancer/about/ what-is-key-statistics.html. Accessed April 3, 2020.

\section{Letter to the Readers: Oncology in the Time of COVID-19 Continued from page 119}

determine who is immune and safe from further infection. This problem has yet to be discussed in detail.

2. No meetings except online. I still miss seeing my colleagues, but safety first.

3. Lack of personal protective equipment. N95 respirator masks and other protective gear are already being rationed and the peak is coming in the next 2 to 3 weeks when demand will explode. Our first responders and healthcare providers are incredibly vulnerable to infection. In China, exposed medical care providers were housed in special dormitories and hospitals to prevent potentially spreading the infection outside, yet this has not been discussed in the United States.

4. Cancelling all nonessential patient interactions and scheduling telemedicine or phone encounters.
5. Rotating our research staff, with half on site and half working at home on alternate days. This buddy system has worked well and now extends to our clinical nursing staff.

6. Continuing routine cancer care and treatment as an "essential service." We will continue to do this as long as we have the necessary personnel and resources and as long as it is deemed safe to bring in these vulnerable patients.

7. Continuing our therapeutic clinical trials also as "essential research." Accrual to nontherapeutic trials has been suspended. The FDA and National Cancer Institute have issued guidelines on clinical trial patient care at local offices and laboratories with remote interactions. Oral investigational agents can be shipped to patients. We will continue this approach as long as we have the personnel and resources necessary.

8. Beginning to triage. Colleagues in Washington State are already making contingency plans to cease treating patients with cancer. We are not thinking in that direction yet but are certain to consider prioritizing potentially curative treatments over "palliative" treatments. Difficult choices are ahead.

The next few weeks will be replete with daily challenges and crises. I encourage you to read the Handbook of COVID-19 Prevention and Treatment which details management policies developed through difficult experience by our Chinese colleagues. The Jack Ma Foundation and Alibaba Foundation have enabled us to download it at https://covid-19.alibabacloud.com.

We will continue, as always, to do our duty to render the absolute best care to our patients and remain healthy ourselves. I extend my heartfelt prayers for your health and safety in the coming days. 


\section{HPV and the Immune System in Head and Neck Cancers: Therapeutic Considerations}

Madison Grinnell'; Mridula Krishnan, MD²; and Apar Kishor Ganti, MD, MS ${ }^{3}$

'University of Nebraska Medical Center, Omaha, NE; '2Division of Oncology-Hematology, Department of Internal Medicine, University of Nebraska Medical Center, Omaha, NE; ${ }^{3}$ Division of Oncology-Hematology, Department of Internal Medicine, VA-Nebraska Western lowa Health Care System, Omaha, NE

\begin{abstract}
Immunotherapy applications for head and neck squamous cell carcinoma (HNSCC) are rapidly evolving. The progress towards immunotherapy has demonstrated improved outcomes for patients with HNSCC. Human papillomavirus (HPV)-associated HNSCC has a much better prognosis and differs from HPV-negative HNSCC in its genomic and immunologic profile, with strikingly higher immune cell activation and infiltration. Despite an increased incidence of HPV-associated HNSCC, and differences in immune signature based on HPV status, the management does not differ from non-HPV tumors. Clinical trials are ongoing to integrate immunotherapy in the management of early- and late-stage HNSCC, and its current use is limited to the metastatic setting. This article describes the role of immune therapy in HPV-associated HNSCC along with the evidence and perspective behind differing therapeutic considerations.
\end{abstract}

Key words: head and neck squamous cell carcinoma, human papillomavirus, immunotherapy, HPV

\section{Introduction}

In the United States, head and neck squamous cell carcinoma (HNSCC) accounts for $4 \%$ of all malignancies; its estimated annual incidence is 53,260, and HNSCC was responsible for 10,750 deaths in 2020. ${ }^{1}$ In addition to the traditional risk factors of alcohol and tobacco use, human papillomavirus (HPV) has been implicated in the pathogenesis of HNSCC. The incidence of HPV-positive oropharyngeal cancer has been increasing in the United States and worldwide. Although HPV positivity is seen in all areas of the head and neck, the majority of evidence on the effect of HPV in cancer biology and prognosis is in the oropharyngeal cancers; estimates from the American Cancer Society suggest that pharyngeal cancers make up about 17,950 new cases and were attributed to 3640 deaths in $2020 .{ }^{1}$ The treatment implications of HPV-associated HNSCC are important, as the risk of death has been shown to be $60 \%$ to $80 \%$ lower with conventional therapy as compared with HPV-negative oropharyngeal cancers. ${ }^{2,3}$

A study published in 2006 by Weinberger et al found that molecular classification suggested a favorable prognosis in a subset of patients with HPV-associated oropha- ryngeal cancers that overexpressed p16 with lower levels of p53 and Rb expression. ${ }^{4}$ The DAHANCA 5 (Danish Head and Neck Cancer Group 5) trial demonstrated that $\mathrm{p} 16$ positivity was associated with a 5-year locoregional control rate of $58 \%$ and an overall survival (OS) of $62 \% .^{5}$ Although conventional treatments including surgery, radiation, and conventional chemotherapy have good efficacy, patients who relapse with distant metastasis often have dismal outcomes. ${ }^{6,7}$ These poor outcomes following relapse after conventional treatment have led to a call for more research into tumor-specific targeted therapy. Immunotherapies offer promising treatment potential as tumors in the head and neck generally infiltrate important structures and complete surgical resection may be difficult, leading to a poor overall prognosis. ${ }^{8}$

\section{Pathogenesis of HPV}

HPV is a virus that can infect the skin and mucosal surface of the oral pharynx, throat, and anogenital region. ${ }^{9} \mathrm{HPV}$ infection is common, and it is thought to occur through mucosal contact with an infected sexual partner. Patients with HPV-associated HNSCC are usually younger and healthier, with less lifestyle risk factors than patients who do not have HPV-driven tumors. ${ }^{10}$ A key aspect of HPV infection and the development of HPV-positive 


\section{TABLE 1. PD-1-Targeted Immunotherapies for HPV-associated HNSCC}

\begin{tabular}{|c|c|c|c|}
\hline Author & Study & Regimen & Results \\
\hline Ferris et $\mathbf{a l}^{33}$ & $\begin{array}{l}\text { Checkmate 141: phase III RCT of } \\
\text { nivolumab vs therapy of investiga- } \\
\text { tor's choice in recurrent or metastat- } \\
\text { ic head and neck carcinoma }\end{array}$ & $\begin{array}{l}\text { Nivolumab compared with } \\
\text { investigator's choice of } \\
\text { cetuximab, methotrexate, or } \\
\text { docetaxel }\end{array}$ & $\begin{array}{l}\text { In patients with HPV-associated tumors, } \\
\text { the median survival was higher with } \\
\text { nivolumab than investigator's choice of } \\
\text { treatment ( } 9.1 \text { vs } 4.4 \text { months; HR, } 0.56,95 \% \\
\mathrm{Cl}: 0.32,0.99 \text { ) }\end{array}$ \\
\hline Cohen et $\mathbf{a l}^{34}$ & $\begin{array}{l}\text { KEYNOTE-040: phase III RCT of } \\
\text { subsequent line of therapy with } \\
\text { pembrolizumab for recurrent or met- } \\
\text { astatic head and neck cancer }\end{array}$ & $\begin{array}{l}\text { Pembrolizumab or standard } \\
\text { treatment (methotrexate, } \\
\text { docetaxel, or cetuximab) }\end{array}$ & $\begin{array}{l}\text { No difference in outcomes with pembroli- } \\
\text { zumab or chemotherapy in patients with } \\
\text { p16-positive tumors (HR, 0.97; } 95 \% \mathrm{Cl}, 0.63 \text {, } \\
\text { 1.49) }\end{array}$ \\
\hline Burtness et $\mathbf{a l}^{\mid 35}$ & $\begin{array}{l}\text { KEYNOTE-048: a study of pembroli- } \\
\text { zumab for first-line treatment of } \\
\text { recurrent or metastatic squamous } \\
\text { cell cancer of the head and neck }\end{array}$ & $\begin{array}{l}\text { Pembrolizumab compared } \\
\text { with EXTREME regimen (cis- } \\
\text { platin or carboplatin, 5-FU, } \\
\text { and cetuximab) }\end{array}$ & $\begin{array}{l}\text { Approximately } 20 \% \text { of patients in this } \\
\text { study had HPV-associated tumors, but a } \\
\text { subgroup analysis was not done }\end{array}$ \\
\hline
\end{tabular}

FU indicates fluorouracil; HNSCC, head and neck squamous cell carcinoma; HPV, human papillomavirus; PD-1, programmed cell death protein 1 ; RCT, randomized controlled trial.

HNSCC is that it occurs in the setting of a persistent HPV infection.

Evolution of cancer is a multistep process whereby cells acquire a number of traits that enables transition from normal to neoplastic behavior. Ineffective immune response results in what may be a protracted state of inflammation. While the heightened immune response should be associated with robust antitumoral activity, the inflammatory response has the paradoxical effect of promoting tumorigenesis. Further intriguing is that the tumor-enhancing effect is disproportionately mediated by cells of the innate immune system.

A recent study conducted by Sonawane et al found that 1 in 9 men between the ages of 18 to 69 was infected with oral HPV. ${ }^{11}$ Several strains of HPV cause infection, some benign and some with high-risk potential. DNA from high-risk HPV strains may be integrated into the genome of the human cell, which can lead to an overexpression of viral oncogenes E6 and E7. Viral oncogene E6 is thought to bind cycle cell-regulatory protein $\mathrm{p} 53$, leading to its degradation and subsequent uncontrolled tumor cell growth. E7 has an additive oncogenic function whereby it binds to and degrades $\mathrm{Rb}$, a tumor suppressor that blocks exit from the G1 phase of the cell cycle, thus regulating E2F transcription factors. ${ }^{12}$
HPV infection is now responsible for the largest number of oropharyngeal tumors in the United States, accounting for $45 \%$ to $90 \%$ of cases. ${ }^{13,14} \mathrm{HPV}$ positivity is detected in $25 \%$ of all HNSCCs. ${ }^{15}$ Notably, survival is markedly higher in patients with HPV-associated HNSCC compared with those with HPV-negative HNSCC (3-year survival rate of $84 \%$ compared with $57 \%$, respectively). ${ }^{16}$

\section{Immune Landscape of HPV- Associated HNSCC}

Research has identified that HPV-positive head and neck cancers are a distinct subset, genetically and molecularly. ${ }^{17}$ There are several mechanisms by which immune evasion in these tumors may be explained. Some of these include interference with antigen presentation, modulation of transcriptional activity of genes, upregulation of cytokines, and interaction of immune checkpoint receptor signaling. HPV-positive HNSCCs have more markers of immune infiltration and CD8+ T-cell activation than HPV-negative HNSCCs, a potential target for harnessing adaptive antitumor immune response systems. ${ }^{18}$ Infection with high-risk HPV types (HPV $16,18,31$, and 33) plays a causal role in the pathogenesis of oropharynx squamous cell carcinoma (OPSCC), and has distinct clinical and molecular features.
More than $90 \%$ of HPV-associated OPSCC in the United States is attributed to HPV high-risk type 16, with rare accounts of HPV type 18, 33, and others reported as responsible in the literature. ${ }^{19}$

In addition to higher levels of CD8+T-cell activation, HPV-positive tumors also have higher expression of perforin and granzyme $\mathrm{A}$ and $\mathrm{B}$, indicating immune activity. ${ }^{20,21}$ Many mechanisms of cell cycle regulation escape have been described in HPV-positive HNSCC, including the development of T-cell tolerance to HPV infection, reduced regulation by interferon gamma, unbalanced signal transducer and activator of transcription (STAT) 1 and 3 signaling, secretion of immunosuppressive cytokines, expression of programmed cell death-ligand 1 (PD-L1), and downregulation of human leukocyte antigen expression and processing which allows the immune system to recognize and tag tumors before destruction. ${ }^{22}$ Higher expression of the immunoinhibitory receptor cytotoxic $\mathrm{T}$ lymphocyte-associated antigen-4 (CTLA-4) has been found in HPV-positive HNSCC $(P=$ $.003)$ and appears to have a correlation with higher regulatory $\mathrm{T}$ cells (Tregs) expression ( $\mathrm{r}=0.866, P<.00001){ }^{17}$

CTLA-4 is a protein receptor that like PD-L1, works to downregulate the immune system's natural response to attack tumor cells and is generally expressed on 
TABLE 2. PD-1-Targeted Immunotherapies Currently Under Investigation in the Treatment of HPV-Associated HNSCC

\begin{tabular}{|c|c|c|}
\hline Clinical Trial/Title & Status & Regimen \\
\hline $\begin{array}{l}\text { Stereotactic Body Radiation Therapy and Durvalumab With or Without } \\
\text { Tremelimumab Before Surgery in Treating Patients with HPV-Positive } \\
\text { Oropharyngeal Squamous Cell Cancer }\end{array}$ & Currently recruiting & $\begin{array}{l}\text { Durvalumab and radiation therapy } \\
\text { with and without tremelimumab }\end{array}$ \\
\hline $\begin{array}{l}\text { Durvalumab Before Surgery in Treating Patients with Oral Cavity or } \\
\text { Oropharynx Cancer }\end{array}$ & Currently recruiting & Durvalumab \\
\hline $\begin{array}{l}\text { Radiotherapy with Durvalumab Prior to Surgical Resection for } \\
\text { HPV-Negative Squamous Cell Carcinoma }\end{array}$ & Currently recruiting & Durvalumab and radiotherapy \\
\hline $\begin{array}{l}\text { Nivolumab, Carboplatin, and Paclitaxel in Treating Patients with Stage } \\
\text { III-IV Head and Neck Squamous Cell Carcinoma That Can Be Removed } \\
\text { by Surgery }\end{array}$ & Currently recruiting & $\begin{array}{l}\text { Nivolumab with weekly carboplatin } \\
\text { and paclitaxel }\end{array}$ \\
\hline $\begin{array}{l}\text { Phase Ib/II of TG4001 and Avelumab in HPV16-Positive Recurrent/ } \\
\text { Metastatic Cancers and Expansion Cohort to Oropharyngeal SCCHN }\end{array}$ & Currently recruiting & $\begin{array}{l}\text { Increasing doses of TG4001 and } \\
\text { avelumab }\end{array}$ \\
\hline $\begin{array}{l}\text { Chemotherapy and Locoregional Therapy Trial (Surgery or Radiation) } \\
\text { for Patients with Head and Neck Cancer (OPTIMA-II) }\end{array}$ & Currently recruiting & $\begin{array}{l}\text { Carboplatin, nab-paclitaxel, and } \\
\text { nivolumab }\end{array}$ \\
\hline $\begin{array}{l}\text { Maintenance Immune Checkpoint Inhibitor Following Postoperative } \\
\text { Chemoradiation in Subjects With HPV-negative HNSCC }\end{array}$ & Not yet recruiting & $\begin{array}{l}\text { Durvalumab or placebo before and } \\
\text { after chemoradiotherapy }\end{array}$ \\
\hline
\end{tabular}

HNSCC, head and neck squamous cell carcinoma; HPV, human papillomavirus; PD-1, programmed cell death protein 1; SCCHN, squamous cell carcinoma of the head and neck.

Tregs. Interferon gamma (IFN-y) has also shown to play a role in HPV-positive HNSCC pathogenesis. Escape from detection by cytotoxic T cells is thought to be related to IFN-y deficiency, which activates STAT1 transcription to prevent tumor escape from regulation. ${ }^{23,24}$

Current research surrounds treatment that may alter the tumor's inflammatory and pro-growth environment, including toll-like receptor stimulation, inhibition of interleukin-6 (IL-6) pathways, immune checkpoint inhibition, and modulation of Tregs and macrophages. ${ }^{25}$ Viral oncogenes $E 6$ and $E 7$ are potential targets for immune intervention, as are $\mathrm{T}$ cells that express programmed cell death protein 1 (PD-1), a marker that has a self-tolerance-promoting and negative regulatory role on T cells, which typically attenuates infective processes and tumor proliferation. ${ }^{26}$

\section{Existing Literature on the Role of Immunotherapy in HPV- Associated HNSCC}

Currently, treatment of HPV-associated oropharyngeal carcinoma resembles non-HPV oral cancers. Although clinical trials evaluating de-escalation of therapy are underway, HPV status does not yet alter the standard treatment course. The current management of oropharyngeal carcinoma utilizes a combination of chemotherapy, radiation, and possibly surgery. However, if patients develop metastatic disease, options are mainly systemic treatments with a palliative intent. There is increasing consensus that HPV-associated HNSCC may benefit from less intensive management regimens; however, presently only retrospective data support this. There are several ongoing clinical trials analyzing de-intensified regimens for HPV-positive oropharyngeal cancer. Overall, the strategies include modification of systemic therapies, surgical procedures, radiation dosing and techniques, and use of immunotherapy or targeted therapies.

Significant improvements in survival have been observed with PD-1 inhibitors in melanoma, non-small cell lung cancer, and renal cell carcinoma. ${ }^{27-29}$ PD-1 and PD-L1 are proteins present on the surface of cells that function to distract the immune system from attacking tu- mor cells. ${ }^{30} \mathrm{HPV}$-positive tumors have increased expression of PD-L1, making PD-1 inhibitors a promising therapeutic option. ${ }^{31}$ Promising clinical trial results led the FDA approval of pembrolizumab for treating refractory or metastatic $\mathrm{HN}$ SCC in 2016. ${ }^{32}$ Patients enrolled in the nonrandomized KEYNOTE-012 trial had metastatic HNSCC, which had progressed despite treatment with standard therapies. A total of $16 \%$ of patients experienced a response to pembrolizumab. In $82 \%$ of these patients, the response lasted for more than 6 months and for several, the response lasted for more than 2 years. $^{32}$

In the phase III CheckMate 141 study, nivolumab treatment resulted in longer overall survival (OS) as a single therapy agent compared with a standard treatment (median OS of 7.5 months compared with 5.1 months, respectively), with estimates of 1-year survival 19\% higher with nivolumab. ${ }^{33}$ For patients with p16-positive status, the median survival in Checkmate 141 was 9.1 months with nivolumab compared with 4.4 months with standard treatment 


\section{TABLE 3. Biomarkers Being Investigated to Predict PD-1/PD-L1 Inhibitor Response}

\begin{tabular}{|c|c|c|}
\hline Author & Biomarker & Result \\
\hline Chow et al, $\mathbf{2 0 1 6}^{38}$ & PD-L1 & $\begin{array}{l}\text { Patients with PD-L1 expression greater than } 1 \% \text { treated with pembrolizumab had a } \\
\text { response rate of } 22 \% \text { vs } 4 \% \text { and a higher median OS ( } 303 \text { vs } 151 \text { days) }\end{array}$ \\
\hline Ferris et al, $2018^{33}$ & PD-L1 & $\begin{array}{l}\text { Nivolumab demonstrated an OS benefit among patients with PD-L1 expression: } \geq 1 \% \\
(\mathrm{HR}, 0.55 ; 95 \% \mathrm{Cl}: 0.39,0.78) ;<1 \%(\mathrm{HR}, 0.73 ; 95 \% \mathrm{Cl}: 0.49,1.09) \text {. }\end{array}$ \\
\hline Hanna et al, $2017^{39}$ & $\begin{array}{l}\text { Inflamed tumor } \\
\text { phenotype }\end{array}$ & $\begin{array}{l}\text { Inflamed tumor phenotype was defined as high/intermediate expression of CD8+ T-cells } \\
\text { and PD-1/TIM3. Median OS was } 9.5 \text { months with PD- } 1 \text { blockade among the inflamed phe- } \\
\text { notype patients, compared with } 2.0 \text { months among the non-inflamed patients }(P=.026) \text {. }\end{array}$ \\
\hline Haddad et al, $2017^{40}$ & $\begin{array}{l}\text { T-cell inflamed phe- } \\
\text { notype }\end{array}$ & $\begin{array}{l}\text { IFN } \mathrm{y} \text { gene expression profile, characteristic of tumor inflammation, was associated with } \\
\text { response to PD-1 inhibitor therapy in HPV-positive patients. In contrast, both the somatic } \\
\text { mutation load and IFN y gene expression profile predicted for response to pembrolizumab } \\
\text { in HPV-negative/EBV-negative patients. }\end{array}$ \\
\hline Hanna et al, $2018^{41}$ & $\begin{array}{l}\text { Tumor mutational } \\
\text { burden }(\mathrm{TMB}) \text { and } \\
\text { frameshift events }\end{array}$ & $\begin{array}{l}\text { TMB was significantly higher among responders with HPV-negative/EBV-negative status } \\
(21.3 \text { vs. } 8.2, P<.01 \text { ), but not among those with HPV-positive/EBV-positive status (median } \\
8.2 \text { vs } 7.3, P=.62) \text {. TMB correlated with OS among virus-negative patients, but not in } \\
\text { HPV-positive/EBV-positive patients. In-frame or frameshift events were more frequent } \\
\text { among HPV-negative/EBV-negative responders but not in those who were virus positive. }\end{array}$ \\
\hline Ayers et al, $2017^{37}$ & $\begin{array}{l}\text { T-cell-inflamed gene } \\
\text { expression profile }\end{array}$ & $\begin{array}{l}\text { A T-cell-inflamed gene expression profile containing } 18 \text { genes (including IFN- } \mathrm{\gamma} \text {-respon- } \\
\text { sive genes related to antigen presentation, chemokine expression, cytotoxic activity, and } \\
\text { adaptive immune resistance) was necessary, but not always sufficient, for clinical benefit } \\
\text { with checkpoint inhibition therapy. }\end{array}$ \\
\hline
\end{tabular}

EBV, Epstein-Barr virus; IFN, interferon; OS, overall survival; PD-1, programmed cell death protein 1; PD-LI, programmed cell death-ligand 1; TIM3, T-cell immunoglobulin and mucin-domain containing protein 3.

(HR, 0.56; 95\% CI: 0.32, 0.99). ${ }^{33}$ The KEYNOTE-040 trial randomized patients to pembrolizumab or standard of care chemotherapy for metastatic HNSCC. The median OS in the pembrolizumab group was 8.4 months compared with 6.9 months in the standard treatment group. ${ }^{34}$ However, in contrast to the results of the CheckMate 141 study, pembrolizumab was not superior to chemotherapy in patients with p16-positive disease (HR, 0.97; 95\% CI: 0.63, 1.49).

The KEYNOTE-048 trial compared survival and disease progression in previously untreated patients with recurrent or metastatic HNSCC given pembrolizumab monotherapy or pembrolizumab with chemotherapy (EXTREME regimen: platinum, 5-fluorouracil and cetuximab). ${ }^{35}$ Data presented recently showed that pembrolizumab monotherapy improved OS by $39 \%(P=.0007)$ in patients whose tumors expressed PD-L1 (combined positive score $\geq 20$ ) compared with chemotherapy. The median OS was 12.3 months versus 10.3 months, respectively. The benefit was higher in patients with a CPS of at least 20, where the median OS was 14.9 compared with 10.7 months (HR, 0.78; 95\% CI: 0.64, $0.96 ; P=.008)$. When pembrolizumab alone was compared with chemotherapy plus cetuximab, the median OS in the total population favored the combination (13 vs 10.7 months; HR, 0.77; 95\% CI: 0.63, 0.93; $P=.0034) .{ }^{35}$ While approximately $20 \%$ of patients in this study were p16-positive, they were not analyzed separately. These studies have been summarized in Table 1. Many trials assessing combination regimens with PD-1 inhibitors and HPV vaccine studies are currently recruiting patients. These studies are outlined in Table 2.

\section{Prediction of Response to Immune Checkpoint Inhibitors}

While tumor mutational burden (TMB) has been investigated as a biomarker to study sensitivity to checkpoint inhibition in different malignancies, PD-L1 expression does not always predict who will have an increased response. More studies are needed, potentially utilizing both TMB and PD-L1 assays, to predict response. ${ }^{36}$ Some of the results assessing biomarkers to predict response to checkpoint inhibitors are shown in Table 3.

Currently, several other markers in addition to PD-L1 expression have been identified and are being evaluated. These include HPV expression, IFN-y signature score, microsatellite instability, and neoantigen production. ${ }^{42}$ IFN-y related mRNA gene expression signatures have predicted clinical response to pembrolizumab in melanoma with some indication that IFN-y and T cell-associated inflammatory genes may predict PD-1 blockade response. ${ }^{37}$ However, none of these biomarkers have consistently shown to be predictive for response to immune checkpoint inhibitors and further studies are needed. 


\section{TABLE 4. Other Immunotherapies Under Investigation for the Treatment of HPV-Associated HNSCC}

\begin{tabular}{|c|c|c|}
\hline Clinical trial & Status & Therapy \\
\hline $\begin{array}{l}\text { Study of HPV-Specific Immunotherapy } \\
\text { in Patients With HPV-Associated HNSCC } \\
\text { (NCT02163057) }\end{array}$ & Completed & $\begin{array}{l}1.1 \mathrm{~mL} \text { of INO-3112 (VGX-3100 + INO-9012) delivered IM via EP } \\
\text { with CELLECTRA-5P device }\end{array}$ \\
\hline $\begin{array}{l}\text { HPV-E6-Specific TCR-T Cells in the Treat- } \\
\text { ment of HPV-positive HNSCC or Cervical } \\
\text { Cancer (NCT03578406) }\end{array}$ & Not yet recruiting & HPV-E6-specific TCR-T cells \\
\hline $\begin{array}{l}\text { Vaccine Therapy in Treating Patients with } \\
\text { Advanced or Recurrent Cancer } \\
\text { (NCT00019110) }\end{array}$ & Completed & $\begin{array}{l}\text { HPV } 16 \text { E7 peptide } \\
\text { Synthetic HPV } 16 \text { E6 peptide }\end{array}$ \\
\hline $\begin{array}{l}\text { HPV Anti-CD40 RNA Vaccine } \\
\text { (NCT03418480) }\end{array}$ & Currently recruiting & HPV vaccine \\
\hline $\begin{array}{l}\text { Study of Monalizumab and Cetuximab in } \\
\text { Patients with Recurrent or Metastatic Squa- } \\
\text { mous Cell Carcinoma of the Head and Neck } \\
\text { (NCT02643550) }\end{array}$ & Currently recruiting & Monalizumab and cetuximab \\
\hline
\end{tabular}

EP, electroporation; HNSCC, head and neck squamous cell carcinoma; HPV, human papillomavirus; IM, intramuscularly, TCR, T-cell receptor.

\section{Other Immunotherapies in HNSCC}

In addition to PD-L1 and CTLA-4 inhibitors, other monoclonal antibodies are being investigated in HPV-positive HNSCC treatment including monalizumab, a monoclonal antibody targeting natural killer group 2 member A (NKG2A). The NKG2A heterodimeric receptor is one of the most prominent NK inhibitory receptors. Monalizumab blocks cancer cells from evading immune system detection by facilitating activation of natural killer and cytotoxic T cells. 43 IL-6 is another target being investigated for use in immunotherapy, as it is thought to play a role in monocyte differentiation to PD-L1+ macrophages which may lower interleukin-12, increase interleukin-10, and have a consequent suppressive influence on
T-cell activation. ${ }^{44}$ Current trials evaluating novel immunotherapies are described in Table 4.

Immunological features of HPV-positive HNSCC suggest that this tumor type has a high potential for responding to immunotherapy, especially with immune checkpoint inhibitors. Given data showing T-cell infiltration in HPV-positive HNSCC, a different approach-one that focuses on checkpoint inhibition-may be beneficial for these patients.

\section{Conclusions}

The results of clinical trials demonstrating response to checkpoint inhibitors in HPV-positive head and neck tumors are promising. Late phase clinical trials are exploring whether the use of immunotherapy in HPV-associated tumors will allow de-intensification cytotoxic therapies. Despite encouraging responses and improved cancer survival rates with checkpoint inhibitors, a significant proportion of patients are still being treated with them and will not respond. Hence, additional predictive biomarkers are needed to differentiate the patients who will respond to immunotherapy. In addition, there is a need for newer immunotherapeutic agents that will improve responses in this difficult-to-treat patient population.

FINANCIAL DISCLOSURE: The authors have no significant financial interest in or other relationship with the manufacturer of any product or provider of any service mentioned in this article.

For full reference list, visit

cancernetwork.com/HPV_HeadAndNeck

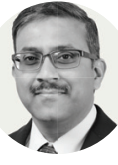

\section{Dr Ganti}

is a professor of internal medicine and biochemistry at the University of Nebraska Medical Center and a staff physician at the VA Nebraska Western lowa Health Care System in Omaha, NE. His laboratory is focused on evaluating new pathways in head and neck and lung cancer and identifying novel prognostic and predictive biomarkers for these malignancies.

\section{Dr Krishnan}

is a second year of fellow in hematology-oncology at University of Nebraska Medical Center. Her research interests are immunotherapy and novel therapies for solid tumor malignancies.

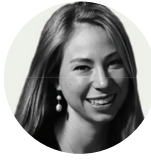

\section{Ms Grinnell}

is a third-year medical student at the University of Nebraska Medical Center in Omaha, NE. She is completing an enhanced medical education Track in Immunology and is active in research with a particular interest in immunotherapy and autoimmunity. 


\section{CONTINUING MEDICAL EDUCATION (CME)}

\section{Minimal Residual Disease and Its Impact on the Clinical Management of Patients With Leukemia}

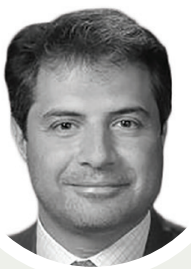

FACULTY

Elias Jabbour, MD

Professor of Medicine

Department of Leukemia

The University of Texas MD Anderson

Cancer Center

Houston, TX

This activity was written by

Physicians' Education Resource, LLC ${ }^{\circledR}$ $\left(\mathrm{PER}^{\circledR}\right)$, editorial staff under faculty guidance and review.

Financial Disclosure Grant Research Support: AbbVie, Adaptive Biotechnologies, Amgen Inc, Bristol-Myers Squibb, Novartis, Pfizer, Spectrum, Takeda

The staff of $P E R^{\circledR}$ have no relevant financial relationships with commercial interests to disclose.

\section{CME PROVIDER CONTACT} INFORMATION

Physicians' Education Resource ${ }^{\circledR}$, LLC 2 Clarke Drive, Suite 110

Cranbury, NJ 08512

Toll-Free: 888-949-0045

Local: 609-378-3701

Fax: 609-257-0705

info@gotoper.com

\section{LEARNING OBJECTIVES}

Upon successful completion of this activity, you should be better prepared to:

- Outline the importance of minimal residual disease (MRD) assessment for the clinical management of patients with leukemia

- Consider the different techniques used to detect MRD

- Implement optimal strategies to use MRD assessment in clinic to optimize the outcomes of patients with leukemia

RELEASE DATE: April 08, 2020

EXPIRATION DATE: April 08, 2020

\section{INSTRUCTIONS FOR PARTICIPATION /} HOW TO RECEIVE CREDIT

1. Read this activity in its entirety.

2. Go to https://www.gotoper.com/go/mrd-leukemia20 to access the online version of the activity and the posttest.

3. You must complete the activity in order to receive a CME certificate.

4. Complete the Posttest and Evaluation, then click on "Request for Credit." You may immediately download a CME certificate upon completion of these steps.

DISCLOSURE POLICY AND RESOLUTION OF CONFLICTS OF INTEREST

As a sponsor accredited by the ACCME, it is the policy of PER ${ }^{\circledast}$ to ensure fair balance, independence, objectivity, and scientific rigor in all of its CE activities. In compliance with ACCME guidelines, $\mathrm{PER}{ }^{\circledR}$ requires everyone who is in a position to control the content of a CE activity to disclose all relevant financial relationships with commercial interests. The ACCME defines relevant financial relationships as financial relationships in any amount occurring within the past 12 months that create a conflict of interest (COI).

Additionally, PER ${ }^{\circledast}$ is required by ACCME to resolve all COI. PER ${ }^{\circledast}$ has identified and resolved all COI prior to the start of this activity by using a multistep process.

OFF-LABEL DISCLOSURE AND DISCLAIMER

This CME activity may or may not discuss investigational, unapproved, or off-label use of drugs. Participants are advised to consult prescribing information for any products discussed. The information provided in this CME activity is for continuing medical education purposes only and is not meant to substitute for the independent clinical judgment of a physician relative to diagnostic, treatment, or management options for a specific patient's medical condition. The opinions expressed in the content are solely those of the individual faculty members, and do not reflect those of PER ${ }^{\circledR}$.

This activity is funded by $\mathrm{PER}^{\circledR}$.

\section{ACCREDITATION/CREDIT DESIGNATION}

Physicians' Education Resource ${ }^{\circledast}$, LLC, is accredited by the Accreditation Council for Continuing Medical Education (ACCME) to provide continuing medical education for physicians. Physicians' Education Resource ${ }^{\circledR}$, LLC, designates this enduring material for a maximum of 0.5 AMA PRA Category 1 Credit $^{T M}$. Physicians should claim only the credit commensurate with the extent of their participation in the activity. 
A cute lymphoblastic leukemia (ALL) is the first neoplasm for which the assessment of early response to therapy by minimal residual disease (MRD) monitoring has proved to be a fundamental tool to guide therapeutic choices.

The clinical impact of MRD is now widely accepted and is regarded today as the most important prognostic factor in the state-of-the-art management of ALL. MRD can provide different information, according to the timing in which it is performed, and can now be refined by the evaluation of additional genomic markers.

Several studies have analyzed the prognostic impact on outcome of MRD-positive status at the time of stem cell transplant, ${ }^{1,2}$ and results of others have shown the prognostic relevance of pretransplant MRD assessment in adults. ${ }^{3-5}$ Bassan et $\mathrm{al}^{5}$ showed that patients with MRD levels $\geq 10^{-3}$ at week 16 and/or week 22 (ie, after consolidation) had a worse posttransplant outcome, with a 6 years' relapse incidence of $64 \%$ compared with $23 \%$ in patients with
MRD levels $<10^{-3}$. A recent meta-analysis of 21 published reports, comprising over 2000 patients, confirms that a pretransplant positive MRD is a significant negative predictor of relapse-free survival, eventfree survival, and overall survival; as expected, a positive MRD prior to transplant was not associated with a higher rate of nonrelapse mortality. ${ }^{6}$ Taken together, these results show that MRD evaluation before transplant is extremely useful for treatment intensification because clinicians can offer the opportunity to adequately use immunotherapeutic compounds aimed at obtaining an MRD-negative status.

The most standardized methods to study MRD in ALL are multi-parametric flow cytometry (MFC) and polymerase chain reaction (PCR) amplification-based methods. Emerging technologies hold promise to improve MRD detection in patients with ALL. To be informative, MRD assays for ALL should be able to detect 1 leukemic cell among 10,000 normal cells or more in virtually all patients. ${ }^{7-10}$

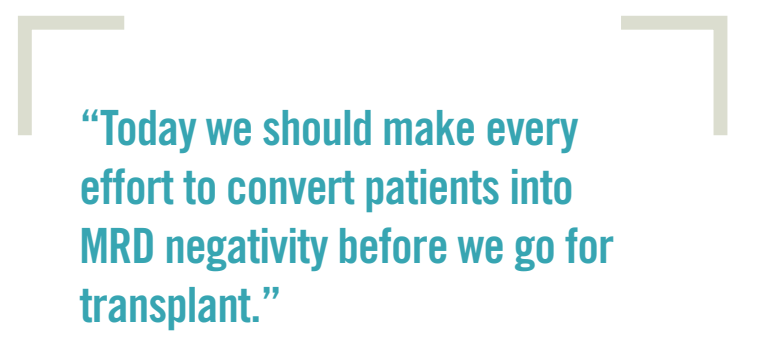

-Elias Jabbour, MD
Testing for MRD has become an established part of the management of ALL, but in acute myeloid leukemia, the technology still warrants validation.

Elias Jabbour, MD, reviews the role of MRD in leukemia and the techniques used to detect MRD. Additionally, Dr. Jabbour discusses the major limitations in the implementation of MRD assessment in clinical practice.

\section{What is MRD, and what is the impact of MRD in the clinical management of patients with leukemia?}

DR JABBOUR: When we have a patient with acute leukemia, specially ALL, and we give them chemotherapy for ALL, $95 \%$ will respond very well. But despite the fact that $95 \%$ will respond very well, in the long run, only $50 \%$ will survive. That means, among these responders, there are patients in whom the disease will come back. That means that most of these patients, of course, yes, are defined as being in complex remission; morphologically, that clone is persistent, and this clone can drive a relapse down the road.

And we call this clone minimal disease. Today we have the tools to measure this disease; therefore, we should no longer call it minimal residual disease but measurable residual disease. When we give chemotherapy to a patient but there's still something measurable, that is still there, and this can drive resistance and can drive relapse, progression, and death.
Therefore, it's important to go beyond the morphology and to dig deep into what we call measurable residual disease. Not only should we be satisfied by what we call morphology, but we should also assess for measurable residual disease.

So now what defines MRD, or measurable disease, is the amount of cells present. And that will bring me to the tools available to us today to assess this disease, and it can be done through different ways. No. 1-what's done in the United States-is flow cytometry. But then we went a level beyond that, what they call NGS, or next generation sequencing.

\section{What is the relevance of MRD assessment in ALL?}

DR JABBOUR: The relevance is that when you have a patient with MRD positivity, the outcome is compromised because the patient has declared themselves as refractory to chemotherapy. These patients are considered high risk. So there are 2 kinds of risk factors in ALL: One is a biology that we cannot modify. Among them, for example, are the cytogenic abnormalities, haplodiploidy, rearrangement, etc. And then we have a second risk: It's how the patient is responding to the treatment. And of course, if you have a good responder, the outcome is better than in a patient who is not a good responder. And here, if you have a measurable residual disease present, that means you're not a good responder. Therefore, that puts the patient in the high-risk category. So high 
risk, therefore, is based on biology and MRD assessment. And I think, as a clinician, I should consider these 2 , put them together in defining the high risk, and decide on a subsequent therapy accordingly.

But the question for MRD is crucial here. Does transplant negate the impact of MRD? In other words, if you have a patient who is MRD positive and you offer them transplant, will their outcome be equal to that of a patient who is MRD negative who did not have a transplant? The short answer is no. When you do transplant, you improve the outcome of patients who are MRD positive, but you do not improve it to the level of patients who are MRD negative. Therefore, transplant did not improvedid not negate- the impact of MRD positivity. Therefore, today we should make every effort to convert patients into MRD negativity before we go for transplant.

In summary, we need to assess for MRD because that tells me the patient has refractoriness, and if it's positive, we should try everything to eradicate this minimal disease. Before transplant, we should consider MRD assessment and treatment. Most of these patients who became MRD negative had a transplant, and the outcome was good. Therefore, we should no longer offer transplant if we have a patient who is MRD positive. We should convert them into MRD negative and then try transplant thereafter. No patients should undergo transplant without our trying to convert them into MRD positive because transplant in a patient with MRD-positive disease is usually associated with relapse post transplantation.

\section{What are the $r$ techniques used to detect MRD?}

DR JABBOUR: In ALL, for example, we measure by flow cytometry, 6 colors to 8 colors. We measure by PCR, and we measure by NGS. Of course, each one has pros and cons. Flow is more commonly available but relies on the expertise of the pathologist, and we do not need to have the baseline samples. PCR is more accurate, but you need a baseline sample to compare, and then it's more laborious. And NGS is the most advanced one; essentially, it's way more sensitive and more accurate.

Q: Some experts think NGS may be a better approach for measuring MRD than flow cytometry. What are your thoughts on this?

DR JABBOUR: Data have shown that patients who can be "identified" as MRD negative by flow can be MRD positive by NGS. Therefore, NGS can give you another level of sensitivity and detecting clones. Why? Because they may have a clone that we missed. Therefore, NGS, in that sense, is a better approach to measure minimal disease compared with flow cytometry. It was approved a year and a half ago, and it's gaining more and more momentum, and I think that should become standard of care.

\section{"We should no longer offer transplant if we have a patient who is MRD positive. We should convert them into MRD negative and then try transplant thereafter."}

-Elias Jabbour, MD

\section{Q: What are the current major limitations in the implementation of MRD assessment?}

DR JABBOUR: I think education is highly needed among physicians who treat leukemias because they need to assess for MRD, number one. Number two, we should familiarize them with the MRD tools available, the assessment tools we have available to us. And they need to know how to interpret a report. And then the timeline-at what point? A month? At 3 months? Anytime? So, again, limitations: accessibility, report interpretation, and being familiar with the system. And finally, really recognize the importance of MRD.

One last example: I know when we do the flow, for example, for assessing for MRD, the first pull from the procedure should be sent to MRD. Otherwise, the rest will be blood, diluted, and it won't tell us anything.

\section{KEY REFERENCES}

2. Campana $D$, Leung $W$.

Clinical significance of minimal residual disease in patients with acute leukaemia undergoing haematopoietic stem cell transplantation. Br J Haematol. 2013;162(2):147-161. doi: 10.1111/bjh. 12358.

3. Zhou Y, Slack R, Jorgensen JL, et al. The effect of peritransplant minimal residual disease in adults with acute lymphoblastic leukemia undergoing allogeneic hematopoietic stem cell transplantation. Clin Lymphoma Myeloma Leuk. 2014;14(4):319326. doi: 10.1016/j. clml.2014.01.002.

4. Hoelzer D. Personalized medicine in adult acute lymphoblastic leukemia. Haematologica. 2015;100(7):855858. doi: 10.3324/ haematol.2015.127837.

5. Bassan R, Spinelli O, Oldani E, et al. Different molecular levels of post-induction minimal residual disease may predict hematopoietic stem cell transplantation outcome in adult Philadelphia-negative acute lymphoblastic leukemia. Blood Cancer J. 2014;4:e225. doi: 10.1038/bcj.2014.48.

6. Shen Z, Gu X, Mao W, et al. Influence of pre-transplant minimal residual disease on prognosis after Allo-SCT for patients with acute lymphoblastic leukemia: systematic review and meta-analysis. $B M C$ Cancer. 2018;18(1):755. doi: 10.1186/s12885-018-4670-5. cancernetwork.com/MRD Leukemia 


\section{Urology Times}

Leading research and analysis.

Practical advice.

\section{www.UrologyTimes.com}

From the publishers of 


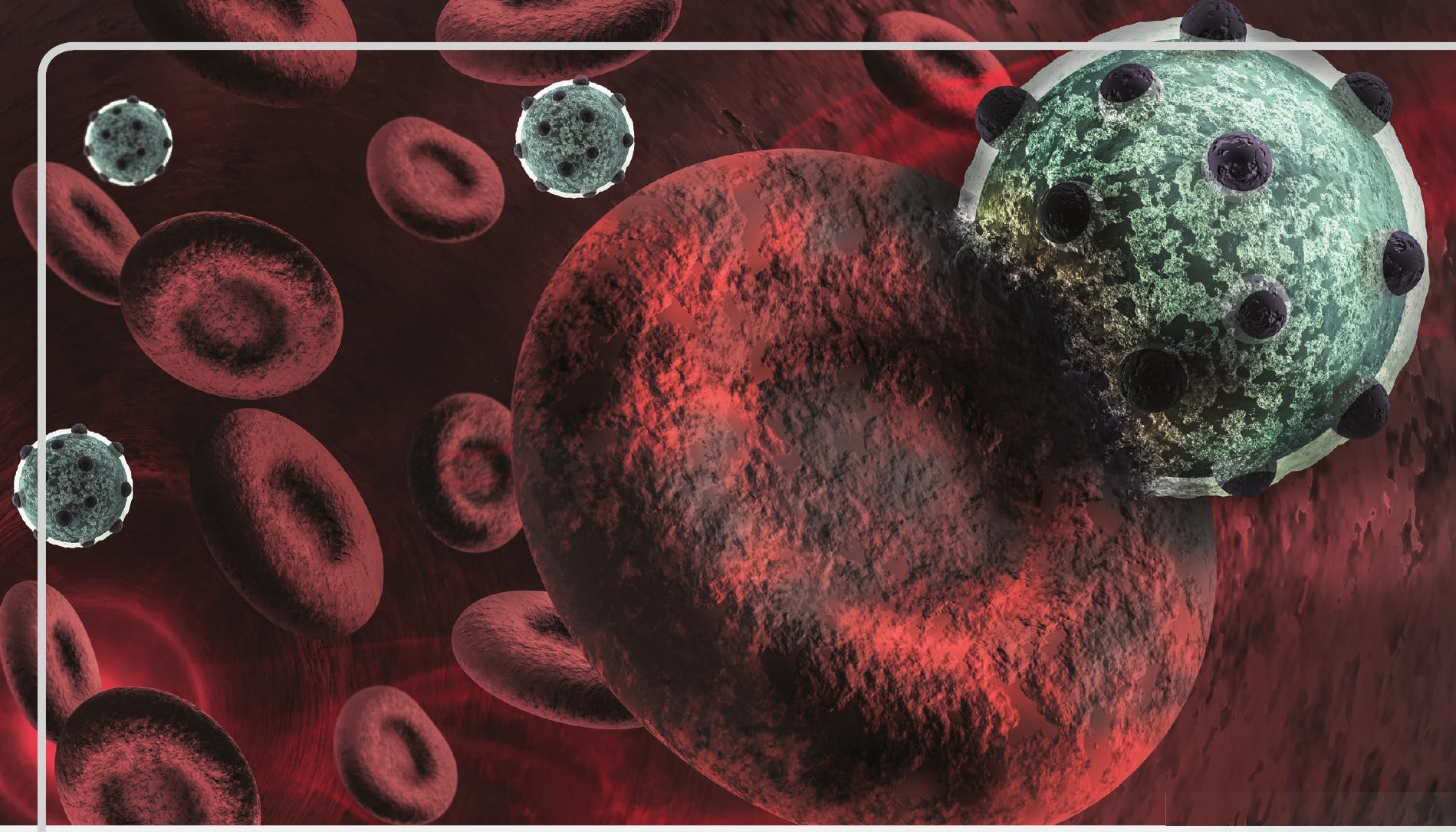

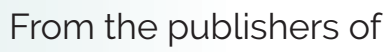

ONCOLOGY

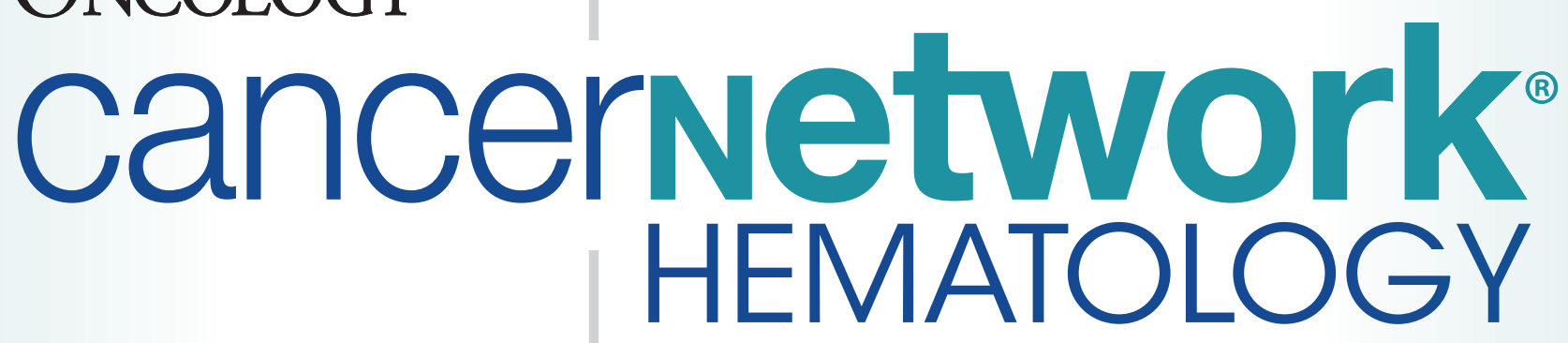

All-new, expanded coverage of hematologic malignancies is available now for the hematology and oncology professional.

- Expanded conference coverage - More up-to-date news

- Deeper coverage of key topics - Available at your fingertips!

\section{CANCERNETWORK.COM/HEMATOLOGIC}

